\title{
Mujeres de Aviación del Ejército Nacional: desligándose de las imágenes estereotipadas ${ }^{1}$
}

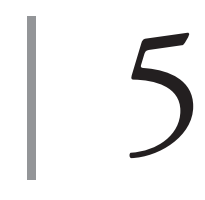

https://doi.org/10.21830/9789585318304.05

\author{
Maria Antonieta Corcione-Nieto ${ }^{2}$ \\ Escuela de Aviación del Ejército \\ Ingrid Yuliana Arango Calderón ${ }^{3}$ \\ Escuela Militar de Cadetes "General José María Córdova”
}

\section{Resumen}

Los estudios sobre las mujeres que integran el Ejército Nacional de Colombia han cobrado relevancia luego de la incorporación de estas a la institución castrense en igualdad de condiciones. Desde ese momento, se ha presentado al grupo de mujeres que integran las filas del Ejército como un grupo pequeño y heterogéneo, casi exótico. Este capítulo, por tanto, se propone comprender, desde los estudios de identidad, la experiencia femenina de integrar el arma de Aviación del Ejército Nacional. En consecuencia, a partir de una encuesta y de un análisis descriptivo de enfoque cualitativo, se pudo establecer que las mujeres del arma de Aviación configuran un grupo variado y complejo, que abarca tanto lo tradicional como lo moderno y que se enfrenta a las mismas presiones impuestas desde el patriarcado. Se pudo concluir que la construcción de la categoría de mujer en el arma de Aviación debe pensarse en plural, alejándose de los estereotipos instaurados dentro de la construcción binaria de lo masculino y lo femenino militar.

Palabras clave: Aviación del Ejército; Ejército Nacional de Colombia; experiencia femenina; identidad; mujeres militares

1 Este capítulo hace parte del proyecto de investigación "El quehacer de las mujeres en el Ejército Nacional de Colombia. Una aproximación desde las experiencias femeninas” del Grupo de Investigación en Aviación Militar, de la Escuela de Aviación del Ejército (ESAVE), registrado con el código COL0077618 de Colciencias. Los puntos de vista y los resultados expresados en este capítulo pertenecen a las autoras y no reflejan necesariamente los de la ESAVE ni los del Ejército Nacional de Colombia.

$2 \mathrm{PhD}$ en Antropología (Universidad de los Andes). Magíster en Biología Humana (Universidad Autónoma de Barcelona). Orcid: https://orcid.org/0000-0002-3509-5519 - Contacto: mariacorcionenieto@cedoc.edu.co

3 Capitán del Ejército Nacional de Colombia. Licenciada en Ciencias Militares y en Gestión Logística de la Escuela Militar de Cadetes “General José María Córdova” (ESMIC). Especialista en Ciencias Militares para la Planificación, del Centro de Educación Militar, Colombia. Orcid: https://orcid.org/0000-0002-5995-9262 - Contacto: ingrid.arango@buzonejercito.mil.co 


\section{Introducción}

La mayor parte de los estudios sobre las Fuerzas Militares se han centrado en aspectos macro, en aquellos temas relacionados con la estrategia, las funciones de las instituciones y su participación en organismos internacionales, entre otros; mientras que los estudios micro, es decir, los referentes al personal militar, a sus características sociodemográficas, sus problemas, sus necesidades y las dinámicas sociales en las que están inmersos, han sido menos numerosos (Gómez et al., 2016) y en algunos contextos, escasos.

En la etapa de la posguerra, luego de la Segunda Guerra Mundial, la sociología militar apareció de forma sistémica, con el objetivo de comprender los procesos sociales que modificaron la estructura de la organización militar a través del establecimiento de criterios sociológicos para el estudio de las fuerzas armadas europeas (Burk, 2002). Las variables de análisis en esta primera etapa tenían como fin dar cuenta del desarrollo interno del desempeño militar a partir de los roles, valores o normas estructurales, la fuerza moral de sus componentes, los aspectos de la educación cerrada, las características privativas del rol del soldado y las relaciones civiles/ militares, principalmente (Malamud, 2013).

La sociología militar, como campo de la sociología, se estableció para dar cuenta de los cambios ocurridos en el proceso de profesionalización de la actividad militar y para demostrar posibles salidas a las problemáticas internas de la organización. De acuerdo con estos objetivos, la sociología militar se ha decantado en tres grandes campos de investigación: las relaciones cívico-militares, la sociología de la guerra y los conflictos entre grupos armados; partiendo de lo militar como un componente más de la sociedad y centrándose en dos vertientes de análisis, el militar como profesional y la institución militar como organización social (Malamud, 2013).

Este desarrollo investigativo no ha sido prolífico en Colombia, debido a que, como lo expone Atehortúa (2004),

la persistente ascendencia positivista sobre los estudios históricos, el escaso desarrollo de la sociología en nuestro país y las circunstancias lógicas de un país en guerra, han afectado de manera particular las investigaciones referidas a la institución militar y sus relaciones con la sociedad civil. (p. 13)

Aun cuando la vinculación entre las ciencias sociales y el ámbito militar ha sido a menudo compleja (Malamud, 2013), se ha iniciado una transversalización de los estudios sociales que - a partir de una dinámica interdisciplinar desde la antropología, la historia, la psicología y la filosofía — ha podido dar explicaciones más integrales y críticas de los fenómenos sociales en la búsqueda de la comprensión del militar como sujeto y lo militar como campo simbólico de lo cultural. 
De acuerdo con Soprano (2013), entre 1999 y 2013, en los artículos publicados en Armed Forces \& Society, uno de los temas principales en los que se centran los estudios de los militares como profesionales (considerando los factores sociales, económicos, políticos y culturales) es el de las identidades, las relaciones, la violencia de género; y dentro de ellos, los estereotipos de género, la masculinidad, las mujeres combatientes, las mujeres militares en operaciones de paz, el rol social de las mujeres militares como combatientes y esposas, los matrimonios entre militares, el divorcio en matrimonios entre militares o de militares y la familia militar.

Como se observa, el tema de las mujeres militares o en contextos militares es un eje central de análisis desde que la mujer incursionó en la carrera militar en los diversos ejércitos occidentales del mundo. Ahora bien, el estudio del tema se ha venido desligando de las preguntas iniciales, vinculadas a exponer los pros y los contras de las aptitudes femeninas para lo militar, así como las condiciones de igualdad en la apertura de las instituciones militares para las mujeres en carrera. En la actualidad, los objetivos de análisis están encaminados a resolver inquietudes más profundas, por ejemplo, en qué medida la feminización de la carrera militar ha generado procesos de toma de conciencia de género; o si ha contribuido no solo a dotar de más poder a las oficiales, sino también a modificar el carácter masculino de la profesión y la práctica militar en lo que se ha llamado la demasculinización de las fuerzas armadas. De igual manera, hoy en día han adquirido preponderancia las preguntas relacionadas con identificar cómo han llegado a ser más igualitarias las relaciones dentro de la institución, es decir, cómo se han democratizado las fuerzas armadas (Bobea, 2008), así como las formas y alcances de estos procesos y las resistencias naturales de cualquier institución a los cambios, que se expresan en lo cotidiano y muchas veces de forma tácita (Donadio, 2018).

Cada rama de las fuerzas armadas de los diversos ejércitos europeos y norteamericanos ha tenido una modalidad diferente de incorporar a las mujeres a sus filas, logrando distintos grados de integración y oportunidades, de acuerdo con las características de cada proceso, sin un sentir común (Villalobos, 2007). Asimismo ha sucedido en el contexto latinoamericano. La incorporación plena de mujeres a las filas militares es un fenómeno muy reciente, asimétrico y diferenciado según países y subregiones (Bobea, 2008). Este puede ser interpretado a partir de dos ejes analíticos que dan cuenta de dinámicas de cambios sociales: los procesos de democratización que a diferentes niveles han tenido lugar en América Latina y el Caribe y los procesos de modernización institucional que se derivan de esos procesos de apertura e inclusión (Bobea, 2003). En las experiencias conocidas, las mujeres oficiales que forman parte del Estado Mayor - y que, por lo tanto, han asumido funciones de mando- son excepcionales (Bobea, 2008, p. 64). 
Más allá de los procesos de incorporación e integración de las mujeres a las instituciones castrenses, está la imagen extraordinaria de las mujeres que se incorporan a las filas y que las configura casi como elementos exóticos. El tokenismo o la búsqueda del caso específico para mostrar en los periódicos y en la televisión a la mujer militar, se repite constantemente. Así, se muestra a la paracaidista, a la tripulante del buque, a la oficial de caballería, a la piloto, entre otras, y no a la médica, la asistente social o la abogada, profesionales que desde hace ya largo tiempo se desempeñan en las fuerzas armadas (Rial, 2009). En este sentido, las mujeres militares de arma terminan siendo hipervisibles como miembros de su grupo e invisibles en tanto que individuos (Bobea, 2008).

Ante esta forma de configurar el papel de las mujeres en el ámbito militar, este capítulo pretende ampliar la visión, desde un estudio micro de enfoque trasversal, de las características sociodemográficas y de conformación de identidad femenina de las mujeres que hacen parte de la Aviación del Ejército Nacional de Colombia. Así, se busca problematizar la percepción de un grupo homogéneo resaltado desde el tokenismo, para desligar las imágenes estereotipadas y presentar la configuración plural y la dinámica de las experiencias de las mujeres pertenecientes al Ejército Nacional de Colombia. Por medio de la indagación de sus perfiles (motivaciones, valores y preferencias), se construye una narración colectiva que las nombra en plural y que permite percibir esta experiencia como transversalmente compartida por un "nosotras" (Elizalde, 2008).

La institución militar fue concebida históricamente, desde el nacimiento de los ejércitos profesionales, como una institución masculina. La pertenencia a ella estaba definida por el sexo. Eran los hombres los que poseían las características que se entendían necesarias para la guerra, y el papel del sexo restante podía a lo sumo consistir en actividades de apoyo. De esta forma, la autoconcepción masculina permanece central en la motivación de los hombres soldados (Donadio, 2018) y constituye la expresión institucional de un proceso que conduce al monopolio del uso de la fuerza en un marco jurídico territorial determinado. Esta expresión institucional del monopolio del uso de la fuerza no debe ser entendida exclusivamente en términos de una cierta capacidad material, sino también en los términos simbólicos que constituyen la identidad de un Estado nación, tanto frente a terceros como frente a su propia población, que se percibe a sí misma como un nosotros, en masculino (Fontana, 2005).

Esta configuración de un nosotros traspasado por lo masculino viene ligada a unas condiciones de vida características. Se sabe que la vida militar no es sencilla, se debe tener una gran vocación para ingresar a la carrera de las armas, pues esto 
demanda un gran sacrificio: traslados continuos, situaciones difíciles que requieren un alto grado de dedicación y, más aún, desde el momento del ingreso se tiene claro que es muy posible llegar a perder la vida (Urrego, 2019).

Es por esto que el ejercicio de la profesión militar supone la formación de la llamada mentalidad militar, que consiste en los valores, actitudes y perspectivas que son naturales al desempeño de la función militar y que van ligadas al sacrificio y al riesgo. La incorporación al cuerpo administrativo no supone la elección de la carrera militar como forma de vida ni una preparación estrictamente dedicada a ello, condiciones básicas de la profesión militar. Por lo tanto, si se asume que es justamente la forma de incorporación masiva (expresado en la forma de ingreso a la carrera militar) la que brinda la homogeneidad y el llamado "espíritu de cuerpo", y que la conducción de las armas está en manos de una oficialidad que expresa la característica distintiva del mando, entonces no existió una incorporación real de las mujeres a las fuerzas militares latinoamericanas antes de los ańos noventa (Donadio, 2004).

Dejando por fuera la compresión del espíritu de cuerpo entre las mujeres, los temas de su participación en las filas o bien se han insertado en otras tradiciones o bien se han estudiado de forma aislada dentro de estas. Hoy en día, la misión de los relatos históricos sigue siendo la construcción de las mujeres como sujetos históricos (Scott, 2008). Constantemente se ha pretendido revalorizar el rol desempeñado por la mujer en las distintas etapas de la historia militar como acompañante, mostrando el espíritu de superación de esta como un acto constante y destacando los casos heroicos de mujeres que, de forma singular en una cultura masculina, han aportado a la construcción de una historia tradicional patriarcal.

En la práctica investigativa se han realizado también trabajos sobre mujeres que han optado por la carrera militar en diversos contextos latinoamericanos. Esto ha sido conflictivo debido a que aún se sigue estereotipando la imagen de las mujeres militares, alejándolas de la configuración de pertenencia a la institución y situándolas en el plano de lo atípico. Por tanto, cabe preguntarse cuál es la imagen que la sociedad quiere ver al pensar en una mujer militar. Desde esta perspectiva, la cultura ha dejado de ser patrimonio exclusivo de un sector social y ha pasado a ser acervo de toda la sociedad, es decir, un elemento configurador de las identidades colectivas y, como tal, un espacio de análisis constante.

Configurar la identidad no es un ejercicio particular, es un nivel de ordenamiento de todas las prácticas sociales (Aguado \& Portal, 1991). Actualmente, existe una crisis general de identidades que afecta, por un lado, a todo el sistema de identidades tradicionales en los países en desarrollo bajo el desafío de la modernización y, 
por otro lado, al sistema de identidades ideológicas, políticas y hasta religiosas que se había configurado en el escenario internacional a partir del avance de la primera década del siglo XX. Por tanto, la identidad en su formulación actual forma parte de la teoría del actor social (Giménez, 1996).

Desde el punto de vista subjetivo del actor social, no todos los rasgos culturales inventariados por el observador externo son igualmente pertinentes para la definición de su identidad, sino solo algunos de ellos socialmente seleccionados, jerarquizados y codificados para marcar simbólicamente sus fronteras en el proceso de su interacción con otros actores sociales. (Pimienta, 2007, p. 62)

La acción de configurar y definir la identidad pasa por la dinámica de la experiencia —en oposición a la representación — y adquiere, en estos casos, el valor de una categoría prediscursiva o extradiscursiva de una realidad que no pasa por la mediación simbólica del concepto: "La experiencia sería la base material-corporal que sustenta un conocimiento vivenciado desde la naturaleza (cuerpo) o desde la biografía (vida): un conocimiento no mediatizado por la ideología de la razón, un conocimiento inmediato" (Richard, 1996, p. 735). Parece ineludible, entonces, que concebir a las mujeres como actores históricos con el mismo estatus de los hombres exige tener una idea de la particularidad y de la especificidad de todos los sujetos humanos. Es así como no se puede utilizar un sujeto representativo universal para las diversas poblaciones de una determinada sociedad o cultura, sin conceder un grado distinto de importancia a un grupo en detrimento de otro (Scott, 2008).

Por consiguiente, una posición ideológica debe conducir a un análisis científico social. Esto es especialmente necesario en la actualidad, "cuando la institución militar experimenta profundos cambios, tanto en su organización interna como en su relación con el resto de la sociedad" (Moskos, 1985, p. 298). Para el caso particular, observar la Aviación del Ejército no es ver a un conjunto de hombres que hacen parte de un pequeño grupo dentro de uno más grande (Urrego, 2019). De igual forma, pensar en las mujeres de la Aviación del Ejército no es simplemente ver a un conjunto de mujeres que hacen parte de un grupo aún más pequeño, dentro de dos más grandes; es, sobre todo, concebir que a partir de la reflexión sobre la condición femenina se afirma el conocimiento de una pluralidad de los modos y los significados de ser mujer (Melucci, 1989).

Ahora bien, aunque aún es un periodo muy corto para medir los cambios sociales que se presentan en las dinámicas de la inscripción de mujeres en las distintas armas del Ejército Nacional de Colombia, este constituye el momento adecuado para afianzar el conocimiento y la comprensión de estas como un grupo 
heterogéneo, muchas veces desligado de las configuraciones estereotipadas de las identidades femeninas. De esta forma, podrá llegar el día en que las mujeres en las Fuerzas Militares ya no sean noticia sino que formen parte de la absoluta normalidad de la vida militar.

\section{Mujeres en el escenario militar: conceptualización de la experiencia femenina}

Lo masculino y lo femenino se constituyen como producciones sociales en un momento dado, producciones que no están exentas de tensiones y se encuentran siempre en movimiento. Estas tensiones parten de las discursividades dominantes y se cristalizan en decálogos religiosos, políticos o científicos, que establecen taxonomías y órdenes ideales que estructuran los pensamientos y las acciones, y que terminan por vivirse como un orden social inmanente y naturalizado como el único posible. Es así como cualquier categoría de grupo social, sujeto, individuo, ser humano, hombre o mujer parte de un determinado marco regulatorio históricamente definido y jerarquizado, que propone las pautas de las relaciones e intercambios sociales (Martínez Herrera, 2007).

En esta definición de las categorías (masculino y femenino), se parte de la fase de la identidad que, cerrada en sí misma y opuesta a todo lo que es externo a ella, se define desde la negación (Melucci, 1989). Se podría pensar que la configuración de la identidad implica negar o suprimir cualquier vestigio de pluralidad y diversidad, lo cual es justamente el germen de todo tipo de proyecto totalitario (Martínez Herrera, 2007); sin embargo, desde la historia de los movimientos, reconocerse desde el pluralismo que conforma toda identidad se vuelve esencial. Así, "cada individuo se apropia de una manera única e irrepetible del contexto histórico-social y deviene como una síntesis singular del propio proceso socio-cultural. La subjetividad es entonces la expresión individualizada de las posibilidades culturales" (Martínez Herrera, 2007, p. 80).

Esta expresión individualizada permite entenderse desde la experiencia como punto originario de la explicación. No son los individuos los que tienen la experiencia, sino los sujetos los que son constituidos por medio de esta. La experiencia es el proceso por el cual se construye la subjetividad para todos los seres sociales. A través de ese proceso, el sujeto se ubica o es ubicado en la realidad social y de ese modo percibe y comprende como subjetivas (referidas a y originadas en uno mismo) las relaciones sociales, considerándolas fuentes confiables de un conocimiento que viene del acceso a lo real por medio de su experiencia (Scott, 2008). 
En este sentido, la experiencia se concibe como un proceso dinámico de construcción de costumbres que surgen de la interacción semiótica con el mundo externo y del continuo compromiso personal-subjetivo, en las prácticas, discursos e instituciones que dan significado (valor, sentido y emoción) a los acontecimientos de la realidad social (Elizalde, 2008, p. 20).

Así, la experiencia modula las trayectorias de los sujetos que, en lo singular, expresan afectos, renuncias, disposiciones, motivaciones, sufrimientos y todo aquello que subjetivamente se invierte en un campo de relaciones donde se disputan capitales que otorga valor, sentido e interés para estar ahí. Sin embargo, las trayectorias no se realizan de manera lineal ni necesariamente articulada con los condicionamientos del campo, sino que se tejen en una trama que otorga memorias, deseos y expectativas en un horizonte abierto a una pluralidad de direcciones y mixturas (González, 2015).

Es por ello que documentar la experiencia ha sido una estrategia muy exitosa en las ciencias sociales. El modo en que cada sujeto vive y se piensa esta mediado por los diversos sistemas de representación que articulan los procesos de subjetividad en formas culturales y de relaciones sociales (Richard, 1996). Cuando la evidencia ofrecida es la experiencia como tal, su reclamo de referencialidad se ve aún más fortalecido, pues ¿qué podría ser más verdadero, después de todo, que el relato propio de un sujeto de lo que (él o ella) ha vivido? Es precisamente este tipo de apelación a la experiencia como evidencia incontrovertible y como punto originario de la explicación el que le quita fuerza al impulso crítico de la historia de la diferencia tal como se venía haciendo en los estudios sobre las mujeres en el pasado (Butler, 1990). Por esta razón, dentro de la experiencia, la vida cotidiana — no solo de las mujeres, pero sobre todo de ellas - incluye muchas maneras de sobrevivir y resistir, de subordinarse y rebelarse que, bajo la apariencia de la apatía y la resignación, tienen un importante significado político (Radkau, 1986).

De esta forma, si el grupo o categoría mujeres debe ser objeto de investigación, entonces el género — los múltiples y contradictorios significados atribuidos a la diferencia sexual- se convierte en un instrumento analítico de importancia (Scott, 2008). El enfoque de género ha llevado a analizar los diferentes papeles que las mujeres han tenido a lo largo de la historia, particularmente, de la historia de la guerra. Durante siglos, los estudiosos han relatado los hechos en clave masculina, ya que eran los hombres quienes los escribían, con lo cual se producía un resultado extraño, pues la población mundial siempre ha estado conformada por hombres y mujeres (Bernad et al., 2013).

Es así como los modelos estudiados ofrecen un abanico que va desde la pasividad de la mujer (recluida en al ámbito doméstico o como principal víctima de la 
situación bélica) hasta la indefinición de género y sexo de la mujer guerrera, pasando por el papel activo de aquellas que sirvieron de un modo u otro en los ejércitos, de quienes participaron como enlaces de guerrilleros o como espías, fueron patriotas en las guerras de las independencias e incluso esposas y amantes de soldados y oficiales (Borreguero Beltrán, 2016).

Aun cuando el enfoque de género ha sido usado en la investigación de lo militar, este ha sido poco comprendido como instrumento de análisis de la realidad de las dinámicas de construcción de identidades de mujeres en el ejército. Esto se debe a que la participación histórica de ellas en las fuerzas militares no tenía un estatuto de reglas comunes a las fuerzas armadas. Solo a partir de su incorporación masiva (Lucero, 2009) en la carrera de las armas, que asegura la participación en condiciones de igualdad y posibilita una óptima contribución profesional a la institución castrense, los análisis de corte transversal de género se empezaron a contemplar y a implementar.

La inclusión de las mujeres en ámbitos estrictamente masculinos, creados por y para hombres, presenta desafíos como la redefinición y ampliación de las nociones tradicionales. En efecto, la institución castrense — cuando forma a sus profesionales, ya sean hombres o mujeres - conforma un tipo humano que está dotado de un determinado ethos, ética e ideología (Almeida Sanguinet, 2015). La socialización de los militares en sus grados de formación aspira no solo a transmitir un conjunto de conocimientos específicos de un campo profesional sino, principalmente, a formar un actor social capaz de representar al ejército (en masculino) como una comunidad moral cualitativamente diferente del común de la gente (Badaró, 2006). Las actitudes ideológicas de las fuerzas militares fluctúan entre dos extremos. De un lado, se encuentran los que ven al militar como un reflejo de los valores sociales dominantes y dependientes totalmente del liderazgo de los civiles. De otro lado, están quienes acentúan las diferencias entre los valores militares y los del resto de la sociedad, y afirman que los militares ejercen una influencia independiente en la sociedad civil (Moskos, 1985).

Este debate sobre la convergencia o divergencia entre las estructuras civil y militar está lejos de agotarse. La convergencia entre ambas estructuras es definida como la tendencia hacia la "civilidad" de los militares; mientras que la divergencia es la tendencia a la militarización y el fortalecimiento de los valores militares tradicionales (Fontana, 2005). Dicho contexto muestra permanentes tensiones entre las visiones más tradicionales de lo militar masculino y las prácticas concretas de las mujeres en las fuerzas armadas, particularmente, en el caso de aquellas que asumen funciones que habían sido históricamente masculinas dentro de la estruc- 
tura castrense (Villalobos, 2007). De esta manera, como una primera aproximación para comprender la formulación convergente-divergente de las fuerzas militares, la sociedad y sus variables, el análisis debe centrarse en la forma en que los miembros pertenecientes a las instituciones castrenses (en este caso, las mujeres) son representativos de la sociedad global.

Las fuerzas militares como institución, con determinadas características que se repiten en diversos contextos temporales y culturales,

son el producto de un proceso histórico que se cristaliza en organizaciones que tienen no solo importantes capacidades materiales sino también importantes componentes valorativos y connotaciones simbólicas que hacen a su funcionamiento interno y a la producción de sentido en el campo social. (Fontana, 2003, p. 2)

De acuerdo con lo planteado por Janowitz (1990), el ejército debe considerarse como un sistema social cuyas características profesionales cambian con el paso del tiempo. En este sentido, la profesionalización de lo militar generó con el tiempo una institución compleja, organizada, con acceso a todos los espacios territoriales, sin embargo, homogénea (Donadio, 2018). Como resultado de esta complejización, "los militares se mueven entre el ámbito privado y el ámbito institucional, caracterizados cada uno por valores, actitudes, marcos estructurales y directrices particulares que organizan a sus miembros" (Gómez et al., 2016, p. 205).

Si bien la institución castrense es resultado de un proceso histórico, se debe considerar como constante la estructura jerárquica de sus integrantes: vertical y eminentemente patriarcal. Alioni (2016) concibe la organización como el lugar donde la institución se encarna, donde se sitúa la autonomía de su funcionamiento, los estilos de autoridad, los juegos de poder y resistencias, pero también, las pasiones.

Como sistema simbólico la institución es unificación de valores, mitos, ritos, ideologías, que operan diferenciaciones, enunciando prohibiciones, definiendo el espacio de lo sagrado y lo profano, en un campo pasional donde se juegan el amor, la muerte y el trabajo; haciendo emerger el orgullo, el ideal de la legítima misión y la vocación salvadora. (González, 2015, p. 13)

Este sistema simbólico se mantiene fijo, como la columna vertebral de las interacciones entre hombres y mujeres que conforman el Ejército Nacional. Por tanto, se aprecia cómo aún, con cambios en las leyes y la infraestructura de las instituciones castrenses, las mujeres militares siguen siendo observadas como diferentes (Pilicita Caiza, 2020). Esto se debe a que la profesión militar supone una "identidad total", que abarca todos los aspectos de la vida de una persona y que posee, además, características peculiares relacionadas con la posibilidad del ejercicio de la 
violencia, con el riesgo físico y con la propia justificación de su existencia, a saber, la visión sobre el conflicto (Donadio, 2010), todo lo cual está asociado a lo masculino.

El ejército viste y calza a un grupo, a los miembros de una institución, no a individuos (Badaró, 2006). El servicio militar obligatorio, por ejemplo, no es solo un hecho que señala el desarrollo del Estado Nacional o el avance en la profesionalización de su aparato armado, sino que también juega un papel en la iniciación y socialización de los soldados en la obediencia, la disciplina, los valores asignados y los conceptos ideológicos transmitidos y creados: "Actúa, igualmente, en las relaciones sociales, en la identidad, en el yo y en la identificación de la amistad, en la idea de colectividad y en la pérdida de individualidad" (Atehortúa, 2004, p. 18).

"Aunque el personal militar representa diferentes tradiciones nacionales, se entiende que la profesión militar muestra patrones comunes en todo el mundo vinculados a valores nacionales, pero también universales" (Malamud, 2013, p. 386), los cuales se cobijan dentro de lo que se estima es el pensamiento militar moderno, con características tales como la fuerza y la valoración de la familia nuclear, entre otras lógicas que se imponen por encima de cualquier manifestación cultural (Vizcaíno Villa, 2019) y que se enmarcan en lo que se considera tradicional.

Se esperaría entonces que en esta colectividad, conformada por el espíritu de cuerpo, no hubiera diferencias entre hombres y mujeres, debido a que las personas deben ser juzgadas no tanto por sus características personales, sino por sus capacidades profesionales para ser aceptadas en la sección, pelotón o compañía. Por tanto, la identidad social de los soldados y, especialmente, su homogeneidad social, se vuelven menos importantes bajo la premisa de que cada uno cumpla con el rol asignado (King, 2014). Sin embargo, el solo hecho de pertenecer a una colectividad no es suficiente para que haya plena identificación, como tampoco lo es tener conocimiento de todo el ideario filosófico y la estructura grupal. Se requiere que los miembros se posesionen en el quehacer; no solo que asuman la teoría, sino que realicen la práctica dentro un sistema ordenado y unificado (Salazar Salazar, 2019).

Es por ello que dicho modelo de naturalización de la relación entre masculinidad e identidad militar se constituyó a partir de universos femeninos y masculinos fragmentarios y excluyentes, necesarios para el sostenimiento del orden institucional consagrado (González, 2015). Como parámetro inicial, la existencia de un control sobre los cuerpos, sobre la manera como crecen, se construyen y se eligen proyecta una sola dimensión de la identidad, basada en elementos predecibles y asignados por los grupos mayoritarios (Vizcaíno Villa, 2019).

En este escenario, el mundo femenino militar (como un concepto unificado y singular) se configuró desde estereotipos identitarios de género, referidos a aquel 
conjunto de ideas simples, previas e irracionales que se atribuyen a las personas en función de su adscripción sexual. Esto último prescribe características definitorias sobre su manera de ser, su identidad, su forma de comportarse y su rol social, según el género como mecanismo activador de la ideología patriarcal.

En este sentido, hay una serie de características, atributos o rasgos de personalidad con una fuerte carga simbólica que señalan que la feminidad es propia de las mujeres y la masculinidad, propia de los varones. Con esto, se les asignan roles y relaciones de poder distintas, en las que se les da mayor prestigio y estatus a las acciones realizadas por los varones que a las realizadas por las mujeres. Los estereotipos de género se refieren al conjunto de creencias, pensamientos o representaciones de lo que significa ser hombre o mujer, y esto incide en esferas como la apariencia física, los intereses, los rasgos psicológicos, las relaciones sociales, las formas de pensar, de percibir, de sentir, así como en las ocupaciones y en otra gran cantidad de factores (Bernad et al., 2013, p. 174).

Así pues, el peso de la historia ha atravesado la problemática de la identidad femenina y determinado las particularidades, entre otras, del rol vocacional y laboral de las mujeres, al tomarlas como un ser humano que tiene por condición ser sacrificado para quedar bien ante sí mismo y ante los demás (Pilicita Caiza, 2020). Aunque la vocación, necesidad y expectativa social se entremezclan y muestran en la actualidad a una mujer en una posición diferente a la de sus abuelas -quienes, en el mejor de los casos, estaban condicionadas por el género para el casamiento y tenían la maternidad como único futuro (Semidober, 2001-2002)—, aún las mujeres se representan en una condición de permanente incompletud, sometidas a una ética de cuidados, de dar, preservar, proteger y reproducir la vida (Facio \& Fries, 2005). Los hombres continúan teniendo prioridad sobre ellas, mientras ellas se postergan a sí mismas, construyendo su identidad en función de esta relación de servidumbre, sometimiento y dominio históricamente dados (Martínez Herrera, 2007).

Esta construcción de la identidad femenina se refuerza en el espacio militar, en el que se resalta la vocación de las mujeres que se integran a la institución desde el pacifismo natural de lo femenino. De igual manera, la vinculación de lo femenino al servicio se convierte en un comparativo del instinto maternal, condición nuevamente considerada natural para las mujeres. Es así como el predominio de características sociológicas institucionales que demandan una vocación sólida de sus integrantes y que, como todas las vocaciones puras, implican una voluntad de servicio, una renuncia y, en definitiva, la aceptación de un sacrificio, se acentúa para las mujeres militares, quienes son encasilladas en roles que refuerzan esta idea. 
Como lo expone Alexiévich (2015) cuando retrata las historias de las mujeres soviéticas que participaron en la Segunda Guerra Mundial: "sabemos sufrir y contar nuestros sufrimientos. El sufrimiento justifica nuestra vida, dura y torpe. Para nosotros, el dolor es un arte. He de reconocer que las mujeres se enfrentan a este camino con valor" (p. 16).

Ante esta conceptualización identitaria militar femenina del valor, el compromiso, pero sobre todo, del sacrificio, se estereotipa a las mujeres que optan por una carrera en las armas. Es por ello que un paso esencial en la contextualización de lo femenino está en comprender a las mujeres como un bloque variado de condiciones y experiencias, anécdotas y transformaciones, que abarcan desde los aspectos más domésticos, formativos o laborales, hasta los sexuales, reproductivos y culturales: "un ideal sería el trascender las referencias y diferencias dicotómicas para crear espacios más diversos y equitativos, con menos etiquetas y luchas por los espacios" (Alejo Jara \& Columé Alonso, 2016, p. 3).

\section{La Aviación del Ejército Nacional: una historia con participación femenina}

En los conflictos contemporáneos, los ejércitos de los países desarrollados cuentan con una aviación propia que, sin usurpar las funciones de la fuerza aérea, procura trabajar en estrecha coordinación para lograr una mayor eficacia en el apoyo a las tropas. Para el caso colombiano, esto se evidencia en las experiencias de las tropas del Ejército Nacional, para las cuales la Aviación del Ejército ha sido decisiva en el cumplimiento de la misión y en la conservación de las vidas, debido a sus apoyos puntuales y oportunos (Urrego, 2019).

En 1995 se ordena la reactivación del arma de Aviación en el Ejército por parte del gobierno del presidente Ernesto Samper (1994-1998). Aunque en años anteriores ya se desarrollaban misiones de aviación en apoyo a las operaciones del Ejército, esta reactivación consolidó la Aviación del Ejército Nacional hasta el día de hoy (Tovar Cabrera, 2020). La creación en 1997 de la Brigada de Aviación N.o 25 , que inicia sus actividades con la participación de aeronaves de ala fija y que luego adquiere las primeras aeronaves de ala rotatoria, permitió el uso de aeronaves en forma más táctica (Tovar Cabrera, 2018). Esto trajo, a su vez, el entrenamiento de nuevas tripulaciones y la acumulación de experiencia para afrontar los diversos retos que suponía el conflicto armado que vivía el país. Con esto se permitió que la institución castrense tuviera sus propios medios aerotransportados (Urrego, 2019). 
[Este hecho] empezó a generar cambios en la institución, los hombres que habían liderado operaciones en tierra, que habían vivido el rigor del combate y del terreno, que habían convivido con los demás camaradas compartiendo los valores y principios de la institución; se convirtieron en los aviadores que trabajarían en una misión más allá del diseño de los sistemas disponibles, con el único fin de satisfacer la necesidad en el campo de combate. (Urrego, 2019, p. 7)

El desempeño del arma de Aviación del Ejército en la proyección de su misión le ha permitido participar permanentemente y de manera decisiva en el conflicto armado interno colombiano contra las organizaciones guerrilleras y de narcotraficantes que delinquen en el territorio nacional (Tovar Cabrera, 2018). Acompañada de su misionalidad, la introducción de helicópteros de manera masiva y sistemática en las operaciones militares creó un impacto novedoso en la institución y un ambiente cultural diferente.

La implementación de la aeromovilidad fue la influencia de muchos elementos, entre ellos, el tecnológico, que generó cambios en los conceptos operacionales, tácticos y doctrinales del Ejército Nacional (Urrego, 2019). Sin embargo, para las otras Fuerzas el proceso fue diferente, de la misma manera que lo fueron las demandas que se experimentaban. La presión para el cambio institucional no se hacía sentir en ellas con la misma intensidad; su propia actividad profesional (en el mar o en el aire) les otorga perspectivas y posibilidades distintas para nuevas conformaciones de identidad (Donadio, 2004).

De este modo, ha sido posible comprender la aparición de hábitos, percepciones y dilemas de un nuevo grupo de aviadores en Colombia, que se identifican con las misiones y la vida diaria de las tropas en tierra. Las acciones individuales realizadas por los pilotos del Ejército parten de unos lazos emocionales y simbólicos entre los integrantes de dicho cuerpo y de las demás tropas de tierra. Estos actos de valor, a su vez, permitieron consolidar la cohesión de grupo (espíritu de cuerpo) como identificación de la institución o imaginario colectivo. Así, el concepto de espíritu de cuerpo ha aumentado su complejidad, añadiendo acepciones como la conciencia, la identidad, la cohesión y la integración social. Dicho concepto parte de una relación social horizontal y vertical a la vez, con elementos organizacionales y componentes institucionales generados por la interacción y las experiencias de sus miembros en las actividades de combate o de la vida diaria en el ámbito militar. Todo ello mantiene un patrón estructurado de relaciones entre sus miembros que, individualmente y de manera colectiva, les permite alcanzar su propósito (GarcíaGuiu López, 2017). 
Para el caso de la Aviación del Ejército, estos hitos en los que se exaltan los actos de valor permitieron crear y alcanzar un ambiente de cohesión difícilmente encontrado en otros grupos, logrando cumplir objetivos comunes en medio de un ambiente de peligro inminente, creando una serie de imaginarios que se vinculan al resto de la institución y se incorporan en el comportamiento colectivo de todo el Ejército (Urrego, 2019). Asimismo, dentro de la construcción de este imaginario que cohesiona al grupo de aviadores, la responsabilidad, la aceptación de normas y deberes, el control de las emociones y el deseo de hacer bien las tareas en pos de una normativa son aspectos muy destacados en las expectativas de un buen piloto (Novis Soto, 1998).

Junto a esta dinámica de conformación de un cuerpo cohesionado de integrantes de la Aviación del Ejército, las políticas de género en el ámbito castrense fueron diseñadas como parte de una estrategia de fortalecimiento institucional democrático y de respeto por los derechos humanos, con la finalidad de eliminar todas las formas de violencia de género y promover una cultura de igualdad de oportunidades (Sosa et al., 2011). Ambos eventos se encuentran en el tiempo, lo que permite su fortalecimiento al momento de la incorporación del primer grupo de mujeres al Ejército Nacional de Colombia en 2009. De este primer grupo de mujeres oficiales, se encuentra la primera mujer piloto de helicóptero (ala fija), a quien le siguieron dos mujeres más. Al día de hoy, participan en la Aviación del Ejército 25 mujeres en ala fija, rotatoria y especialidades (tabla 1).

Tabla 1. Mujeres oficiales del arma de la Aviación del Ejército Nacional (año 2020)

\begin{tabular}{lcccc}
\hline & \multicolumn{3}{c}{ Grado } & \multirow{2}{*}{ Total } \\
\cline { 2 - 4 } & Capitán & Teniente & Subteniente & \\
\hline Ala fija & 1 & 3 & 2 & 6 \\
Ala rotatoria & 0 & 3 & 6 & 9 \\
Especialidad & 2 & 5 & 3 & 10 \\
\hline Total & 3 & 11 & 11 & $\mathbf{2 5}$ \\
\hline
\end{tabular}

Fuente: Elaboración propia

La participación de mujeres en la Aviación del Ejército muestra el paso progresivo que se experimenta al momento de su incorporación en espacios destinados a 
los hombres, lo que se puede denominar metafóricamente como el derrumbe de un muro. La tendencia ha sido que las mujeres se empleen cada vez más en diversos ámbitos castrenses, y más en el arma de Aviación que en las otras, debido a que en la primera el sexo no es un factor distintivo, principalmente, porque en ella prima la tecnología frente al factor físico. En el caso de la selección de pilotos, este proceso se ha ido adaptando con el paso del tiempo a los nuevos requisitos del rol, como consecuencia de la configuración y diseńo de las modernas aeronaves y de las demandas del contexto de seguridad y defensa (Novis Soto, 1998).

A pesar de este imperativo, la participación femenina en este ámbito tecnológico y profesional de la Aviación se presenta como un espacio de difícil acceso para ellas, por lo cual se trata de una conquista tratada y significada con diferentes parámetros al caso masculino, es decir, desde el tokenismo. No es raro que se encuentren dos discursos que, sin ser contradictorios en sí mismos, reflejen valores socioculturales diferentes sobre los vuelos y pilotajes de hombres respecto de los de las mujeres. En los primeros se sanciona el arrojo y el valor, la técnica y el conocimiento. En ellas, sin embargo, la valentía se transformó en escapismo a la norma, en caprichosa decisión personal, en terquedad incluso; mientras que su sexo y la imagen que se construyó socioculturalmente se enmarca una y otra vez en los imperativos de género, entre ellos, el de la belleza, con todos los rasgos que le son propios a esta cualidad: gracia, estilo y elegancia.

Tanto ellas como sus acciones se valoran con discursos singulares que, lejos de igualarlas con sus compañeros varones, ahondan aún más la brecha de exclusión social que todas ellas sobrellevan. Gracias a esto, se refuerzan los modelos culturales que hablan de complementariedad entre los sexos (Moncó Rebollo, 2018), y se rescatan los valores de esfuerzo, disciplina, sacrificio y, sobre todo, vocación (El Ejército tiene a la primera mujer piloto de un helicóptero Black Hawk, 2018), todo lo cual las aparta de los roles tradicionales femeninos y las sitúa nuevamente en la idea de habitar espacios no creados para ellas.

Por ello, las mujeres militares se esfuerzan por una carrera en la que no desean privilegios ni contemplaciones, sino más bien igualdad de oportunidades (Donadio, 2010). Para entender mejor esto, el primer paso es comprender quiénes son estas mujeres que deciden tener una carrera militar y así poder reconocerlas como un grupo heterogéneo, de múltiples motivaciones y experiencias diversas. De esta manera, cada una de las armas, en especial, la Aviación del Ejército, podrá configurar un espacio equitativo. 


\section{Métodos}

Con el fin de abordar la problemática sobre la comprensión del grupo de mujeres que pertenece al arma de Aviación del Ejército Nacional, esta investigación de enfoque cualitativo desarrolló un proceso metodológico en el que se combinó el análisis bibliográfico exhaustivo de diversas fuentes y bases de datos con el análisis de datos cualitativos y cuantitativos obtenidos de una encuesta. Esta última tuvo como objetivo caracterizar sociodemográficamente a las entrevistadas e indagar sobre la profesión militar, el liderazgo y los derechos de las mujeres oficiales y suboficiales del arma de Aviación y de aquellas que han sido asignadas a esta arma en labores especializadas y de apoyo como criterio de inclusión.

Este tipo de investigación resulta conveniente para comprender los fenómenos desde la perspectiva de quienes los viven, generando así un entendimiento desde la experiencia femenina y su significación en espacios masculinos. En este sentido, se asumió una investigación exploratoria no solo para comprender el perfil de las oficiales y suboficiales de la Aviación del Ejército, sino también para obtener un insumo que permita la toma de decisiones en el proceso de incorporación, permanencia y desarrollo de la carrera militar de las mujeres.

La encuesta fue aprobada por el Comité de Ética en Ciencias Sociales y Exactas (CECSE) de la Escuela Militar de Cadetes "General José María Córdova” y fue validada por pares expertos. Se aplicó a 71 mujeres, con una participación del $50,7 \%$ del cuerpo administrativo y un 49,3\% del cuerpo de las armas (figura 1), conforme a lo cual se obtuvo una tasa de respuesta del $100 \%$ de las mujeres que integran el arma de Aviación del Ejército. Finalmente, se realizaron análisis estadísticos mediante el programa SPSS, versión 26.

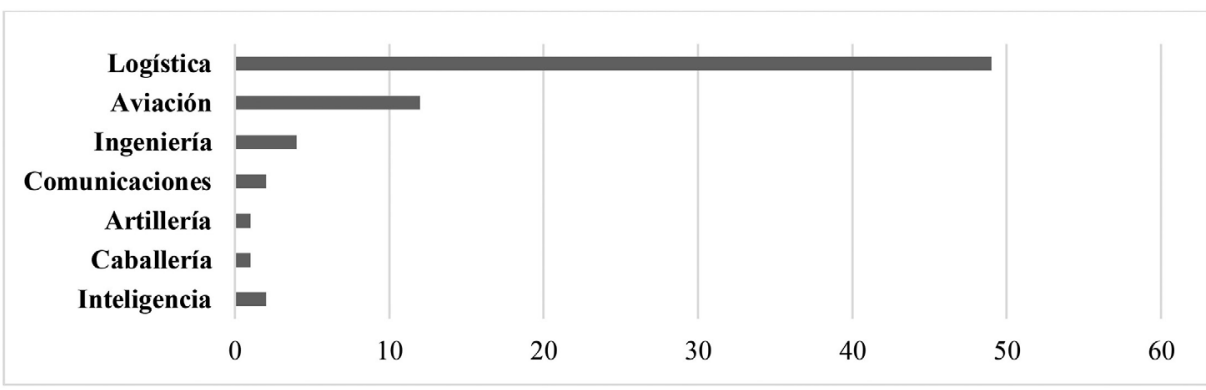

Figura 1. Número de mujeres oficiales y suboficiales pertenecientes a las diversas armas en las unidades de Aviación del Ejército Nacional (año 2020) que participaron en el estudio.

Fuente: Elaboración propia 


\section{Resultados}

Debido a que el nuevo paradigma de las Fuerzas Militares debería proveer a sus integrantes de referentes identitarios (normas, valores, discursos, símbolos y tradiciones) que les permitan pensarse al mismo tiempo como militares y ciudadanos de una sociedad democrática (Colotta, 2013), el análisis de la conformación del grupo de mujeres que integran las filas del arma de Aviación del Ejército Nacional se hace primordial.

Como se ha establecido, la institución militar, considerada fundante y paradigmática en la vida social — por ser lugar político de producción y reproducción de sujetos modulados en prácticas de subordinación- (Alioni, 2016), permite configurar, antes que las características individuales de las mujeres, lo que se percibe como lo más destacado del género. En otras palabras,

La carencia de individualidad descrita, es característica de los procesos de incorporación de minorías o grupos que han sido previamente excluidos. Para el ambiente receptor, la calidad de pertenencia a este grupo es extraordinaria, en el sentido de ser fuera de la norma habitual y, adicionalmente, ser notoria a primera vista. (Villalobos, 2007, p. 14)

De esta forma, para extraer de la conceptualización identitaria unificada a la mujer real oficial y suboficial del arma de Aviación del Ejército Nacional, es preciso reconocer, en primer lugar, la composición sociodemográfica a la que esta pertenece: cuál es su estado civil y el número de hijos, si los tiene. Así mismo, es necesario identificar la conformación de sus familias, su linaje militar y sus valores humanos, para vislumbrar desde la propia experiencia femenina la construcción del grupo de mujeres que escogen pertenecer al Ejército Nacional de Colombia de forma pluralista y diversa.

\section{Composición sociodemográfica de las mujeres de la Aviación del Ejército}

El grupo de mujeres que pertenecen a la Aviación del Ejército está conformado por $37(52,1 \%)$ oficiales y 34 suboficiales (47,9\%) (figura 2). Las edades de las mujeres se encuentran entre los 20 y los 40 años (figura 2), con un mayor porcentaje de mujeres entre los 26 y los 30 años (40,8\%); seguido por el grupo de mujeres con edades entre los 21 y 25 ańos (29,6\%); con porcentajes menores (mayores al 10\%) de mujeres entre los 31 y 40 años (figura 2). Esta relación de los grupos de edad de las mujeres se debe a que la incorporación femenina a la carrera 
de las armas se inició hace tan solo 11 años (en 2009), por tanto, ellas no están ocupando altos puestos en la jerarquía militar, sino que llegan a capitán, como el grado más alto entre las mujeres de arma.

En cuanto a los lugares de nacimiento de las mujeres militares encuestadas, estos se encuentran en su mayoría en la Región Andina, donde el departamento de Cundinamarca (16,9\%), la ciudad de Bogotá (15,5\%) y el departamento de Boyacá $(12,7 \%)$ son los lugares con mayores porcentajes; seguidos por el departamento del Tolima (9,9\%) (figura 2). Por el contrario, en la Costa Atlántica (solo representada por los departamentos de Magdalena y Atlántico) y en la Costa Pacífica (departamentos de Nariño, Cauca y Valle del Cauca) son pocas las mujeres que pertenecen a la Aviación del Ejército (figura 2). De igual manera, en la región de la Orinoquía apenas un 4,2 \% de ellas (Meta) pertenece la Aviación, y del Casanare solo hay un 2,8 \%. Ninguna mujer de la Aviación es proveniente de la Amazonía (figura 2).

Asociado al lugar de nacimiento, las mujeres encuestadas se identifican como mujeres blancas (40,8\%), mientras que más de la mitad de la muestra de mujeres se concibe como mujer mestiza (59,2 \%). En el censo nacional realizado en 2018, los departamentos con mayor población que se reconoce a sí misma como afrocolombiana, raizal o palenquera son Valle del Cauca (1.092.169 de personas), Antioquia (593.726 personas) y Cauca (256.022 personas) (Becerra Elejalde, 2019). Son pocas las mujeres de estos departamentos que pertenecen al Ejército Nacional, especialmente, al arma de Aviación, lo que devela la ausencia de afrocolombianas en las filas. Caso similar es el de la representación militar de mujeres indígenas, que conforman solo un 4,4\% de la población total colombiana (Departamento Administrativo Nacional de Estadística [DANE], 2019).

\section{Estado civil y características familiares de las mujeres de la Aviación del Ejército}

Referente al estado civil de las mujeres pertenecientes al arma de Aviación, se observa que más del $40 \%$ de las mujeres están solteras sin pareja (figura 3). El resto de la muestra tiene pareja, ya sea porque están solteras con pareja $(28,2 \%)$, comprometidas (5,6\%), en unión libre (9,9\%) o en matrimonio (12,7\%) (figura 3). Para el caso de las mujeres con pareja, el 78,57\% de estas pertenece a las Fuerzas Militares; de estas el 82 \% es miembro del Ejército Nacional (figura 3).

Esta situación del estado civil de las mujeres es una tendencia general en la sociedad. La actividad laboral femenina se ha generalizado en la mayor parte de las naciones occidentales, asemejándose, cada vez más, a la de los hombres. Asimismo, 

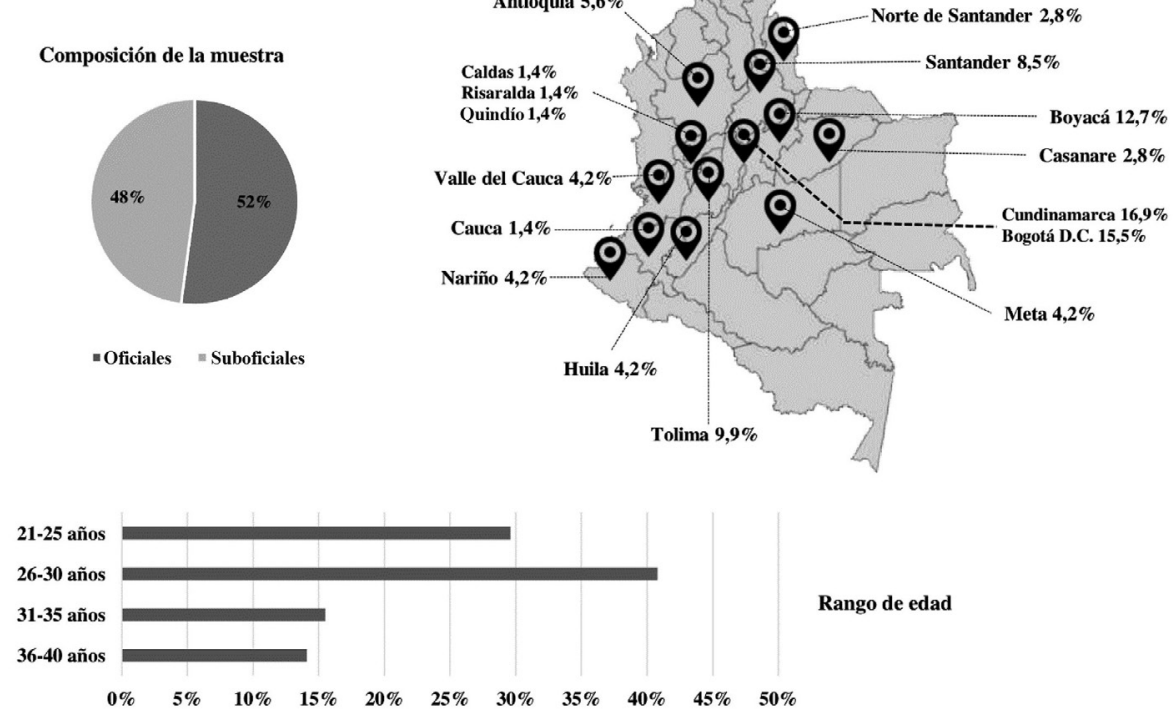

Figura 2. Composición de la muestra de mujeres encuestadas, rangos de edad y lugar de nacimiento.

Fuente: Elaboración propia

numerosos estudios corroboran la importancia que tiene para la mujer el ejercicio de un trabajo remunerado fuera del hogar, no solo por la función económica que este provee, sino también porque desarrolla el sentido de la autonomía, la independencia y la autosuficiencia (Rodríguez Menéndez \& Fernández García, 2010).

El ingreso a la universidad o la elección de carrera y la experiencia de formación profesional han posibilitado la emergencia de sujetos femeninos que se configuran a través de la profesión como mujeres con capacidades y posibilidades de individualización y desarrollo, lo que las aleja de los referentes domésticos y maternales que se han impuesto sobre la identidad femenina. En esta etapa, se observa la desvinculación del trinomio femenino-instinto-maternidad. Lo anterior da lugar a sujetos con una idea distinta sobre vivirse como mujer, que tiene su origen en el proceso de socialización en la familia, pero que toma fuerza como parte medular del proceso subjetivo de estas mujeres en el trayecto universitario y el posterior ingreso al mercado laboral. Por lo tanto, el trabajo profesional asalariado y, en este caso, la vinculación a la institución castrense contribuyen a la constitución de un 
sujeto mujer con referentes y proyectos de vida alejados de los modelos de esposas y madres (Castañeda Rentería, 2019).

En las sociedades actuales se abraza el individualismo como valor más que en cualquier sociedad del pasado. "El tránsito por el mercado sexoafectivo se vuelve aún más complejo para la mujer: si bien necesita encontrar pareja para adquirir valor, no puede mostrarse muy dependiente o desesperada, ya que estos son atributos indeseables en el sistema social" (Gorlero, 2020, p. 27). De acuerdo con esto, la mayoría de mujeres se imagina una vida en pareja como parte del imaginario de felicidad. Lo importante es que el final feliz esté en el horizonte, y la soltería no está construida como un horizonte de felicidad para las mujeres, debido a que socialmente se discrimina a las solteras independientemente de su situación particular.

Aún con el incremento de quienes viven en soltería, ya sea como modo de vida o porque no hay lugar a convivir en pareja, hay evidencia de que también se da una idea estereotipada acerca de este estado. Comparadas con las personas que están casadas, se percibe a las solteras como más inmaduras socialmente, egoístas, pobremente ajustadas, poco o nada atractivas y asociales. La única visualización positiva es que son vistas como más independientes y orientadas al trabajo (García Meraz et al., 2012).

Es así como "la relación entre hombres y mujeres padece ahora un dilema central: por un lado, existe el deseo y la obligación de ser un individuo independiente; por otro lado, se da la necesidad de una convivencia duradera con otras personas que, sin embargo, a su vez están sujetas a las prefiguraciones y expectativas de su propia vida” (Beck \& Beck-Gernsheim, 2001, p. 111).

En esta dicotomía en la que se encuentran principalmente las mujeres, entre la realización profesional y la vida en pareja, se desarrollan las identidades femeninas que están en constante tensión, principalmente, en la carrera militar. No solo son las horas dedicadas al trabajo, sino que la naturaleza de la profesión militar plantea cuestiones sobre la experiencia, las emociones y el poder personal. La participación en lo militar requiere un alto grado de compromiso con la institución castrense, pero la diferencia de género hace que las mujeres y los hombres negocien estas demandas de forma distinta.

Como lo plantea Franzway (2000), concebir los aspectos de la participación de las mujeres en las instituciones castrenses puede entenderse a través de un enfoque del ejército como una "institución codiciosa". Estas instituciones buscan exclusividad y lealtad de sus miembros, así como el compromiso activo en el consumo de su tiempo y energía, ocupando cada vez más de su vida hasta que no quede espacio para nada más. Esto se logra mediante mecanismos no coercitivos, al cultivar el 
cumplimiento voluntario como un medio para que sus miembros se sientan partícipes de la institución (Sullivan, 2014). En este sentido, las mujeres asumen tres aspectos principales al pertenecer a una institución codiciosa: el compromiso, la carga de trabajo y la labor emocional. Según esto, se entiende que exista un gran porcentaje de mujeres solteras entre las filas militares.

En un estudio realizado por Harrell y Miller (1997) en las distintas Fuerzas Militares estadounidenses, si bien no fue posible determinar la frecuencia con la que las citas o las relaciones sexuales se presentaban en las unidades militares, cuando estas relaciones ocurrían, se afectaba la moral de la tropa. Aquellas relaciones que se calificaron como fraternización fueron tratadas por la cadena de mando. Sin embargo, las relaciones personales entre compañeros que no están en una cadena de mando no suelen violar las regulaciones, a menos que afecten el buen orden y la disciplina. De acuerdo con lo planteado por este estudio, la existencia de tales relaciones generó un entorno sexualizado, lo que dificultó que los colegas se consideraran como compañeros de trabajo, aunque se estipuló que es algo inevitable teniendo las características propias del entorno militar.

Al igual que en las Fuerzas Militares de los Estados Unidos, en el Ejército Nacional de Colombia no se sancionan las relaciones afectivas entre compañeros, pero sí la fraternización entre militares bajo la cadena de mando. Esta misma dinámica de pertenecer a una institución codiciosa como el Ejército hace que las relaciones sociales y afectivas surjan de los mismos espacios compartidos por hombres y mujeres, quienes comprenden el nivel de compromiso y la carga de trabajo. Pasar los días en un trabajo de jornada laboral de ocho horas lleva a la mayoría de los adultos a pasar un mínimo de 1680 horas al año en la oficina, por lo que es probable que pasen más tiempo con sus compañeros de trabajo que con cualquier otra persona (Filgueira, 2018); para el caso de las mujeres y hombres militares las jornadas laborales son más extensas. Por tanto, la proximidad es el factor que debe ser considerado como la causa principal, ya que trabajar cerca potencia la atracción interpersonal. Esta proximidad tiene tres clasificaciones: proximidad física, proximidad como resultado de las exigencias del trabajo en curso y proximidad de los encuentros casuales (Colombo \& Patitucci, 2016). Todas estas se cumplen en los escenarios militares, dadas las características de la carrera militar, que incluyen confinamiento y una alta tasa de traslados.

No obstante, aunque la meta de muchos es el matrimonio o la vida en pareja, la estructura de la familia ha estado sujeta a cambios durante las últimas décadas. El cambio más notable es que la tasa de matrimonios sigue en descenso. Para la muestra analizada, solo el $12 \%$ de las mujeres están casadas y se encuentran entre 

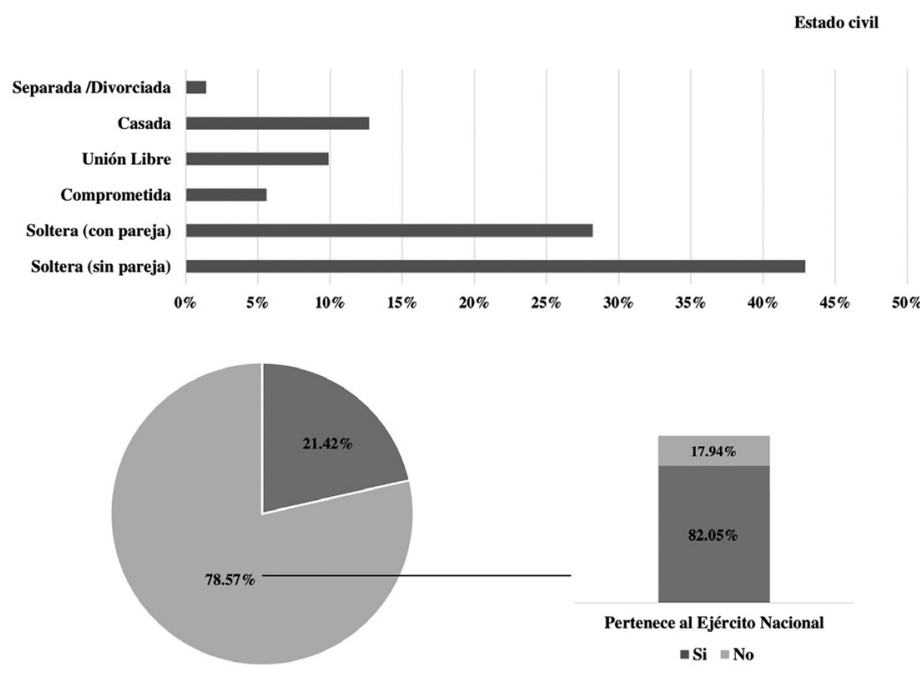

Pareja no milita

- Pareja militar

Figura 3. Estado civil de las mujeres militares de la Aviación del Ejército y pertenencia de parejas a las Fuerzas Militares.

Fuente: Elaboración propia

los rangos de edad superiores a los 26 años (tabla 2), tendencia que siguen hombres y mujeres en la sociedad colombiana, en la que por cada 100 matrimonios se registran 41 divorcios en promedio. Según los datos registrados en la Superintendencia de Notariado y Registro (SNR), entre 2016 y 2019 se presentaron un total de 214.596 matrimonios y 88.118 divorcios (Collazos, 2020).

Tabla 2. Número de mujeres de la Aviación del Ejército por rangos de edad y estado civil

\begin{tabular}{lcccc}
\hline \multirow{2}{*}{ Estado civil } & \multicolumn{4}{c}{ Rangos de edad } \\
\cline { 2 - 5 } & $\begin{array}{c}\mathbf{2 1 - 2 5} \\
\text { ańos }\end{array}$ & $\begin{array}{c}\mathbf{2 6 - 3 0} \\
\text { años }\end{array}$ & $\begin{array}{c}\mathbf{3 1 - 3 5} \\
\text { años }\end{array}$ & $\begin{array}{c}\mathbf{3 6 - 4 0} \\
\text { años }\end{array}$ \\
\hline Casada & 0 & 3 & 4 & 2 \\
Comprometida & 0 & 3 & 0 & 1 \\
Divorciada/Separada & 0 & 0 & 0 & 1 \\
Soltera con pareja & 5 & 11 & 2 & 2 \\
Soltera sin pareja & 14 & 11 & 4 & 1 \\
Unión libre & 2 & 1 & 1 & 3 \\
\hline
\end{tabular}

Fuente: Elaboración propia 
De acuerdo con esta tendencia a prolongar la unión en pareja y planear la maternidad, más de la mitad las mujeres pertenecientes al arma de Aviación del Ejército no tiene hijos (67,6\%), mientras que el 22,5\% tiene un hijo, el 8,5\% tiene dos hijos y solo el 1,4\% (una mujer) tienen tres hijos (figura 4 ).

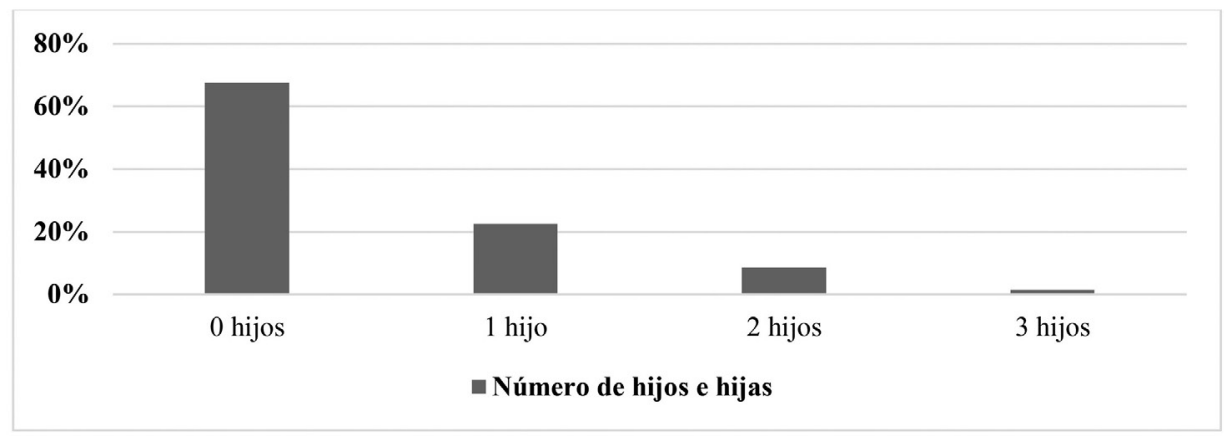

Figura 4. Número de hijos e hijas de las mujeres de la Aviación del Ejército.

Fuente: Elaboración propia

$\mathrm{Al}$ asociar el estado civil de las mujeres encuestadas con el número de hijos, se encuentra que las mujeres solteras con y sin pareja son las que no tienen hijos aún (tabla 2). Cabe resaltar que las mujeres solteras sin pareja encuestadas son, la mayoría de las veces, madres cabeza de familia; de estas, seis tienen un hijo o hija y dos mujeres tienen dos hijos o hijas (tabla 3). Si bien, las mujeres entre los $20 \mathrm{y}$ 25 años de edad no tienen hijos, se observa que existe un número significativo de mujeres cabeza de familia entre las oficiales y suboficiales de más de 26 años.

Tabla 3. Estado civil de las mujeres oficiales y suboficiales y su número de hijos

\begin{tabular}{lcccc}
\hline \multirow{2}{*}{ Estado civil } & \multicolumn{4}{c}{ Número de hijos e hijas } \\
\cline { 2 - 5 } & $\mathbf{0}$ & $\mathbf{1}$ & $\mathbf{2}$ & $\mathbf{3}$ \\
\hline Casada & 3 & 4 & 2 & 0 \\
Unión libre & 3 & 2 & 2 & 0 \\
Comprometida & 3 & 1 & 0 & 0 \\
Separada/divorciada & 0 & 0 & 0 & 1 \\
Soltera con pareja & 17 & 3 & 0 & 0 \\
Soltera sin pareja & 22 & 6 & 2 & 0 \\
\hline
\end{tabular}

Fuente: Elaboración propia 
Por otra parte, en el último censo realizado en el país, el aumento de mujeres madres cabeza de familia sigue en crecimiento. En 2017, cerca de la mitad de las mujeres del país (56 \%) eran madres solteras (López, 2018). Los casos de mujeres cabeza de familia del arma de Aviación son bajos, debido probablemente a que las mujeres militares, al inscribirse en una institución codiciosa en la que el compromiso y la carga de trabajo se imponen, deben entrar en conflicto con los proyectos de vida que incluyan la maternidad. Por otra parte, la tendencia de las mujeres en el país es tener su primer hijo a los 27 años en promedio, lo cual está asociado al mayor acceso a la educación y a la participación en el mercado laboral, tal como sucede entre las mujeres del arma de Aviación (“Colombianas están postergando la edad para ser madres: Dane", 2019).

$\mathrm{Al}$ igual que el ejército, la familia es otra institución codiciosa (De Angelis \& Segal, 2015). El nivel de compromiso que se debe tener para la constitución de una familia (en el sentido tradicional, compuesta por una pareja y descendencia) implica nuevamente un dilema en los proyectos de vida de las mujeres militares. Por esta razón,

las mujeres están más preocupadas por lograr un empleo que sea compatible con sus obligaciones familiares. Diversas investigaciones concluyen que uno de los factores que las mujeres tienen más en cuenta cuando eligen un puesto de trabajo es que este sea compatible con las responsabilidades familiares. Para el caso de los varones, los factores principales que condicionan su elección profesional son el sueldo o las oportunidades de promoción. (Rodríguez Menéndez \& Fernández García, 2010, p. 260)

Aunque socialmente se está consolidando el principio del reparto igualitario de las labores domésticas, en la realidad, la proporción de hombres que lo ejercen es minoritaria, pues es la mujer quien las asume en mayor parte.

Además, a pesar de que el trabajo productivo es fuente de satisfacción para la mujer, también le genera estrés y ansiedad, debido a los problemas derivados de la conciliación. En la imagen idealizada de la maternidad, impuesta en los roles de género de cuidado y del desarrollo de una relación intensa de afecto entre madres e hijos, las mujeres deben apartarse muchas veces de su carrera profesional para desempeñarse como madres y esposas. Separadamente, la familia y las fuerzas militares imponen demandas sustanciales en sus miembros; la intersección de estas dos instituciones sociales crean el potencial de desbordamiento, tanto positivo como negativo, y el conflicto principalmente para las mujeres (De Angelis \& Segal, 2015).

Este conflicto puede ser resuelto postergando la maternidad o eliminándola de los proyectos de vida femeninos o, por el contrario, renunciando a la carrera 
militar. En el análisis de la situación laboral de los conyugues o parejas militares, se encontró una enorme influencia en sus vidas de que sus parejas pertenezcan de forma simultánea a dos instituciones codiciosas. En ocasiones, el hecho de que estas no quieran o no puedan renunciar a su empleo hace que se limiten a sí mismas de alguna manera y orienten sus carreras a buscar la estabilidad geográfica y así lograr mantener la estabilidad familiar (Gómez et al., 2016). Ya que no se han realizado estudios suficientes sobre mujeres militares, proyectos de vida y vida en pareja, se debe indagar más entre aquellas que integran las diversas armas del Ejército Nacional.

Por otra parte, se les preguntó a las mujeres encuestadas si tenían personas a su cargo ${ }^{4}$. El 36,6 \% de las mujeres de la Aviación tiene personas a su cargo, entre las que se cuentan padres, abuelos, hermanos y sobrinos (figura 5). En el $73 \%$ de los casos, las mujeres se ocupan de sus padres; en un porcentaje menor $(7,69 \%)$ se ocupan de sus hermanos, y en porcentajes similares se ocupan de más familiares, como hermanos y sobrinos (figura 5).

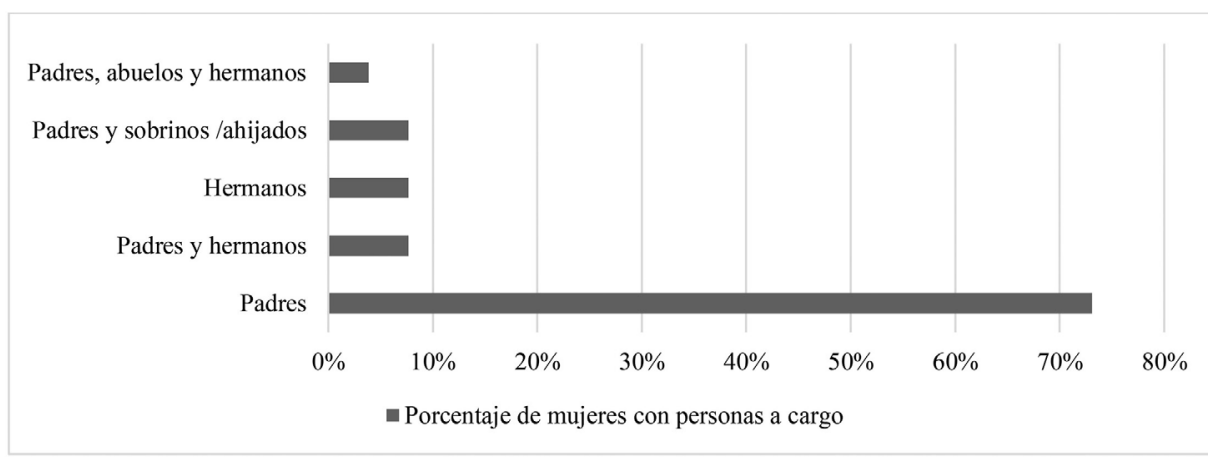

Figura 5. Porcentaje de mujeres de la Aviación del Ejército con personas a cargo. Fuente: Elaboración propia

$\mathrm{Al}$ momento de establecer si las mujeres con o sin hijos tienen personas a su cargo, se observa que ocho mujeres sin hijos tienen personas a su cargo, en este caso, sus padres (tabla 4). Las mujeres sin hijos o con un hijo o hija son las que más personas a su cargo tienen. Se esperaría que las mujeres sin hijos fueran las únicas dispuestas a establecer una relación de cuidado con sus parientes cercanos; sin embargo, lo que se observa es que independientemente del número de hijos e

4 Las personas a cargo son aquellas cuya subsistencia o sostenimiento depende de un contribuyente. Para este caso de estudio, no se considera a los hijos como personas a cargo. 
hijas de las mujeres de Aviación, estas tienen personas a su cargo (Prueba de Fisher: 12.890 y p:0.001).

Asimismo, cuando se indaga sobre la posible relación entre el estado civil de las mujeres y tener o no personas a su cargo, se encuentra que no la hay. Las mujeres casadas o con pareja, también tienen alguna persona a su cargo (Prueba de Fisher: 4.596 y p: 0.483). Al igual que la idea anterior, se esperaría que las mujeres solteras fueran las más dispuestas a mantener a una o varias personas, dado que los solteros son más allegados a sus familias, cuidan a sus padres y tienen más posibilidades de disponer de su tiempo de la manera que más les convenga y que se ajuste a sus actividades (García Meraz et al., 2012).

Para profundizar en este tema, se plantea también si existe una asociación entre la práctica de una religión (en este caso, la católica) y el que el 87,3 \% de las encuestadas asuman personas a cargo. En este caso, no hubo asociación estadísticamente significativa (Prueba de Fisher: 4.366 y p: 0.076). De igual manera, no hubo asociación entre considerarse una mujer espiritual y tener a cargo personas o familiares (Prueba de Fisher: 5.517 y p: 0.115). De igual manera, no hubo relación entre tener personas a cargo y la adscripción a una familia tradicional o moderna (Prueba de Fisher: 0.558).

Esta situación permite pensar en la carga que se ha impuesto sobre las mujeres de la labor del cuidado solo por el hecho de ser mujeres. Para este estudio, se comprende que no existe un contexto del cuidado en el que sea la mujer militar la que renuncie a su carrera para dedicarse al cuidado de las personas a su cargo. Aun así, la idea de tener personas a cargo trae consigo el eufemismo de ser mujer, es decir, esta tarea de solidaridad primaria, fundamental para la sociedad, todavía sigue siendo asignada a la mujer como condición natural de su género. Esto se apoya, a su vez, en el rol de género que las mujeres han debido asumir tradicionalmente, un rol que, fundamentado en la división sexual del trabajo y en estructuras psicosociales que lo legitiman, han interiorizado y reproducido, en mayor o menor medida, a lo largo de toda su vida (Mier et al., 2007).

$\mathrm{Al}$ encontrarnos en una sociedad que envejece a causa, entre otras dinámicas, del aumento de la esperanza de vida y la disminución de la fecundación, se debilitan las estructuras familiares entre las diversas generaciones (Bazo, 2008). Esto ha permitido, por un lado, que las dinámicas de cuidado se establezcan y, por otro, que aumente la diversidad de las formas familiares, las normas y las costumbres. 
Tabla 4. Relación entre el número de mujeres con número de hijos e hijas y personas a su cargo

\begin{tabular}{lcccc}
\hline \multirow{2}{*}{ Personas a su cargo } & \multicolumn{4}{c}{ Número de hijos e hijas } \\
\cline { 2 - 5 } & $\mathbf{0}$ & $\mathbf{1}$ & $\mathbf{2}$ & $\mathbf{3}$ \\
\hline Padres & 8 & 8 & 2 & 1 \\
Hermanos & 0 & 2 & 0 & 0 \\
Padres y hermanos & 1 & 0 & 1 & 0 \\
Padres, abuelos y hermanos & 1 & 0 & 0 & 0 \\
Padres y sobrinos/ahijados & 1 & 1 & 0 & 0 \\
\hline Total & 11 & 11 & 3 & 1 \\
\hline
\end{tabular}

Fuente: Elaboración propia

Según estas tendencias de transformaciones y rupturas del grupo familiar, la idea de familia, que se encontraba íntimamente ligada a los conceptos de unidad doméstica y hogar, hoy se reconoce en su complejidad y dificultad para ser delimitada, dada la multitud de definiciones existentes y la percepción que cada grupo social tiene de esta. Es en la familia donde se definen las dimensiones básicas de la seguridad humana: los procesos de reproducción y de integración social de las personas (Golovanevsky, 2006). Central para esta discusión es entender que la familia (en todas sus acepciones) cumple la función de ser el medio por el que surge la identidad personal, los valores y normas de los individuos que conviven en ellas.

Los tipos de familia o la composición familiar de las mujeres militares de Aviación encuestadas corresponden en más de la mitad a padres casados o en unión libre $(67,6 \%)$, le siguen las familias de padres separados o divorciados $(21,1 \%)$, con una baja representación de familias monoparentales de madres cabeza de familia (7 \%). En este caso, no existe representación de familias extensas, conformadas por abuelos y tíos entre las mujeres encuestadas (figura 6), contrario a la tendencia nacional en la que la estructura familiar extensa se ha convertido en un tipo de familia sobre la estructura de hogar biparental (De la Torre Galvis, 2013).

Asociados a estos nuevos modelos de familia, están los modelos de familia tradicionales entre las mujeres de la Aviación del Ejército (81,7\%), así como las estructuras familiares democratizantes (85,9\%) (figura 6). El modelo de familia tradicional se configura desde la idea de composición de una pareja y su descendencia, unidas en un conjunto de valores y creencias similares. Es por ello que, aunque la composición familiar sea extensa, el 39,6\% considera que existe un 
modelo tradicional de valores. En cuanto a la composición familiar nuclear, el $60,3 \%$ tiene un modelo tradicional. Esta composición de valores de las familias tradicionales o modernas no se encuentra asociada con la práctica de alguna religión (Prueba de Fisher: 0.057).

Los complejos y profundos procesos vividos por la sociedad colombiana a lo largo del siglo XX impactaron y trasformaron las estructuras y las dinámicas familiares; dichos procesos comenzaron a mediados del siglo XX con la reducción del tamaño de la familia y la salida de las mujeres del espacio doméstico (Pachón, 2008). Es importante anotar cómo este proceso de transformación de las familias en Colombia se percibe entre ambas generaciones (mujeres encuestadas y sus madres). Las mujeres militares provienen de hogares constituidos por ambos padres casados o en unión libre, y las mujeres militares en su mayoría están solteras, en respuesta (como ya se anotó) a su inscripción en el espacio laboral, en este caso, la carrera militar que se inscribe como una institución codiciosa.

El cambio más notorio entre ambas generaciones de familias de las mujeres militares es el aumento de hogares con jefaturas femeninas (madres cabeza de familia) y el crecimiento de la participación económica de las mujeres, así como la emergencia en el plano simbólico de nuevos modelos de familia. Golovanevsky (2006) anota al respecto que estas son las principales transformaciones del modelo de familia latinoamericana. En este caso, el país se ha convertido en los últimos años en el lugar de América Latina donde hay un menor porcentaje de niños viviendo con los dos padres, con un $62 \%$ de familias monoparentales. Asimismo, tiene el mayor porcentaje de parejas viviendo en unión libre, con un 35\%, y también el mayor porcentaje de niños nacidos de madres que no se han casado, con un $84 \%$ (“Colombia, primero en Latinoamérica en nuevos tipos de familia”, 2016). Aunque estas cifras no son similares para el caso de las mujeres militares, es evidente el cambio en la composición de las familias en las que se criaron las mujeres militares y las nuevas composiciones de familia que ellas conforman hoy en día.

Otra de las transformaciones que han sufrido las familias colombianas es la disminución de sus miembros. Hoy por hoy, se tienen menos hijos en cada familia. Para el caso de las mujeres encuestadas, solo dos (2,8 \%) son hijas únicas; mientras que el resto tiene al menos un hermano o hermana (tabla 5). En promedio, las mujeres encuestadas tienen 1,44 hermanos varones y 0,83 hermanas mujeres; por dos hermanos hay una hermana entre las mujeres encuestadas. Para 1978, las familias estaban conformadas por 4,9 personas, cifra que se redujo a 4,6 para 1985 (Profamilia, 1991), rango de años de nacimiento en los que se encuentran las mujeres de la Aviación del Ejército. Este patrón reducido de familia es el que presentan los miembros de las familias de las mujeres militares de Aviación. 
Composición familiar

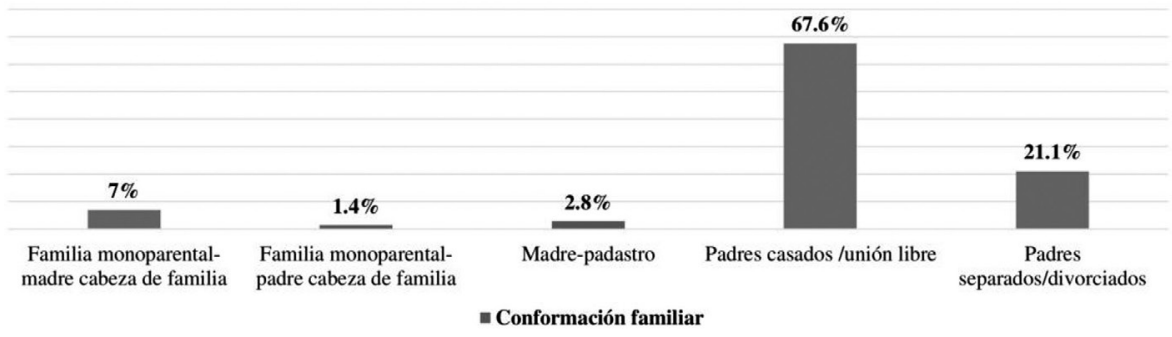

Modelo de familia

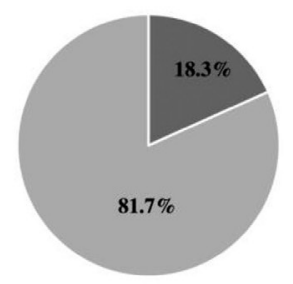

" Moderna " Tradicional
Estructura familiar

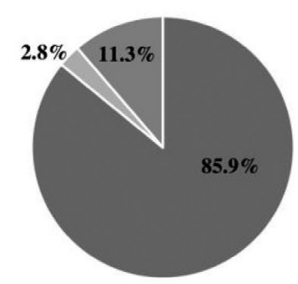

-Democratizante = Machista $=$ Matrifocal

Figura 6. Composición familiar. Modelo y estructura familiar de las mujeres de la Aviación del Ejército.

Fuente: Elaboración propia

Tabla 5. Porcentaje de mujeres de Aviación y el número de hermanos y hermanas

\begin{tabular}{lll}
\hline & Hermanos & Hermanas \\
\hline $\mathbf{0}$ & $19,7 \%$ & $42,3 \%$ \\
$\mathbf{1}$ & $46,5 \%$ & $42,3 \%$ \\
$\mathbf{2}$ & $18,3 \%$ & $8,5 \%$ \\
$\mathbf{3}$ & $5,6 \%$ & $5,6 \%$ \\
$\mathbf{4}$ & $5,6 \%$ & 0 \\
$\mathbf{5}$ & $4,2 \%$ & $1,4 \%$ \\
\hline
\end{tabular}

Fuente: Elaboración propia

En cuanto a la tasa de fecundidad de estos mismos rangos, entre 1984 y 1986 la tasa se estimó en 3,2 hijos, mientras que entre 1987 y 1990 la tasa descendió a 
2,9 hijos por mujer (Profamilia, 1991). Esta tendencia se ha sostenido a lo largo de las décadas. En 2005 la tasa de fecundidad era de 2,5 hijos por mujer (DANE, 2005). Para 2012, las familias de estrato 3 estaban conformadas por cuatro miembros (entre padres e hijos), pero este número sigue disminuyendo (“¿Cómo es la nueva familia colombiana?”, 2012); para 2018 es de 3,4 personas por familia (García \& Jaramillo, 2018).

De acuerdo con estas circunstancias, el grupo de mujeres de la Aviación del Ejército se sitúa en la transición de la configuración familiar que presenta una reducción de su tamańo por la disminución de la tasa de natalidad (debida, entre otras razones, a la inscripción de estas al mercado laboral). Aunque las madres de las mujeres pertenecientes al Ejército en su mayoría (figura 7) solo poseen título de bachiller $(53,5 \%)$, más de la mitad tiene o tuvo trabajo remunerado (49,3\%) (figura 7); en cuanto al trabajo no remunerado, ya sean labores del hogar o el cuidado de otros, un 19,7\% de las madres de las mujeres encuestadas se encuentra en este rango (figura 7).

Esta transición de roles femeninos y composición familiar ha tenido a las mujeres bajo enormes presiones, porque mientras la economía les envía un único mensaje (sal a trabajar y gana el dinero que necesita la familia para sobrevivir), las viejas tradiciones culturales les envían otro: quédate en casa y cuida de los nińos (Thurow, 1997). Los niveles de escolaridad logrados por la mujer, su inserción en el mercado laboral, la conciencia de sus derechos y sus potencialidades, así como la homologación en la edad de los cónyuges, condujo a establecer relaciones más igualitarias y de mayor cooperación dentro de la familia, con lo cual quedó atrás la sumisión impuesta a la mujer por la religión y la cultura imperantes (Pachón, 2008).

Se ha argumentado que la modernización ha modificado las estructuras familiares y sus funciones, así como ha producido cambios en las obligaciones filiales; sin embargo, en la realidad aún las mujeres (incluidas las pertenecientes a la Aviación) siguen bajo las presiones heredadas. Para el caso de la estructura familiar (figura 6), aunque existe una mayoría de estructura democratizante que apoya la idea de las relaciones más igualitarias y de mayor cooperación familiar, aún madres de las mujeres encuestadas participan de un ambiente bastante religioso. Si bien la asociación no es estadísticamente significativa (Prueba de Fisher: 1.883 y p:0.854), es importante aclarar que la configuración de identidad femenina dentro de los ambientes familiares se encuentra en una tensión entre las nuevas estructuras familiares y los modelos tradicionales que incluyen una alta religiosidad. Coincidiendo con lo expuesto por López (2003), las configuraciones familiares existentes en cada sociedad se reconocen como efecto de las inercias y transformaciones del acumu- 
lado histórico de una cultura, depositaria de los valores e ideales que regulan los tipos, los ritos y las responsabilidades sociales instituidas para garantizar la producción y reproducción de los miembros de una sociedad.

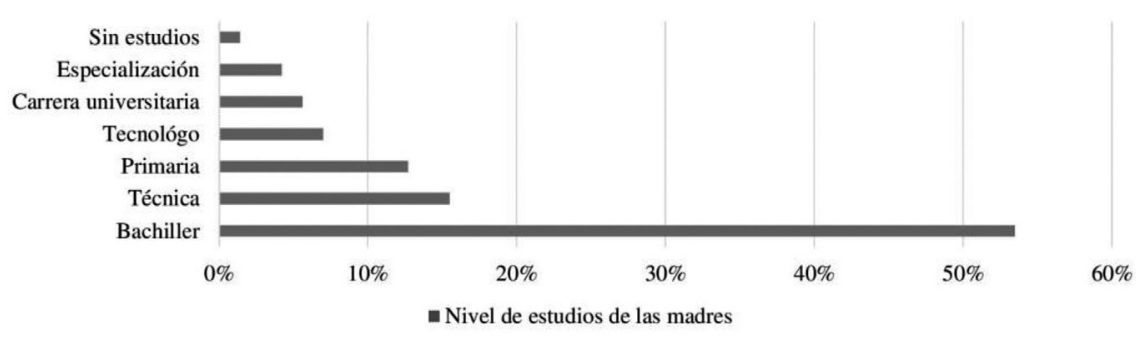

Situación laboral de las madres

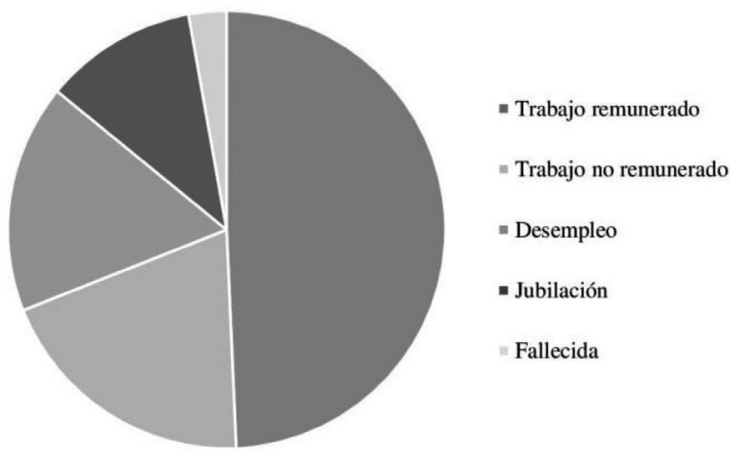

Figura 7. Nivel de educación y situación laboral de las madres de las mujeres de la Aviación del Ejército.

Fuente: Elaboración propia

Por consiguiente, entre los cargos que más tiempo asumieron las madres de las encuestadas, se encuentra que el $33,8 \%$ es ama de casa (trabajo no remunerado); el 16,9\% se desempeña o desempeñó como trabajadora independiente; el $7 \%$ fue o es docente y el 5,6\% es o fue comerciante. En cuanto a las labores profesionales se encuentran administradoras (2,8\%), odontólogas (1,8\%), psicólogas $(1,8 \%)$, trabajadoras sociales $(1,8 \%)$ y auxiliares de cocina $(1,8 \%)$, entre otras.

Aunque los cambios familiares a mediados del siglo XX implican la reducción del tamaño de la familia y la salida de la mujer al espacio laboral, persistieron como ideal viejos conceptos y continuaron vigentes realidades de épocas anteriores. La familia religiosa, legalmente constituida y durable "hasta que la muerte los separe" continuaba siendo un ideal en la mente de amplios sectores sociales 
(Pachón, 2008), ideario que se replica entre las mujeres pertenecientes a la Aviación del Ejército. Sin que exista una asociación estadísticamente significativa entre el modelo de familia (moderno o tradicional) y la situación del trabajo de las madres de las mujeres de Aviación (Prueba de Fisher: 3.983 y p:0.385), se comprende que las nuevas configuraciones familiares corresponden a las exigencias económicas a las que se enfrentan las familias, acompañadas del cambio de imagen de la religión, cuyas metas y ritos han perdido influencia sobre la comunidad y, en especial, sobre la mujer. En el ambiente nacional se sintió el debilitamiento de la ética religiosa en la vida familiar (Gutiérrez de Pineda, 2005), sin que con ello se pongan en duda los valores y creencias religiosas.

Ante esta dicotomía de conformación de familia e identidad, es notoria la asociación de los trabajos remunerados con los trabajos que se han considerado femeninos (concentrados en las áreas de humanidades y artes, ciencias sociales, derecho, salud y educación) entre las madres de las mujeres militares. A pesar de ello, se observa un pequeño porcentaje de madres que pertenecieron al Ejército Nacional $(2,8 \%)$ y a la Policía Nacional (2,8\%) (figura 8$)$.

Estudios realizados a militares encuentran que la tradición familiar sigue pesando en la elección de la carrera militar. Dentro las motivaciones, la familia toma un valor especial, muchos tienen en sus respuestas la orientación dada por algún pariente que estuvo en la institución y que le trasmitió esa emoción que se vive en el día a día de la vida castrense. Desde nińos escucharon historias que les generaron el gusto por la institución, el uniforme y las armas; además de la transmisión de los valores propios de la institución por parte de un familiar o amigo cercano (Urrego, 2019); sin embargo, la tendencia más significativa es la no pertenencia a una familia de tradición militar. Esta es la situación que se presenta entre las mujeres de la Aviación del Ejército, cuyos padres y madres no pertenecieron a las Fuerzas Armadas en un 70 y un 81,7\% respectivamente (figura 8). Cuando se extiende el análisis del linaje familiar a los abuelos, tíos y hermanos, se presenta el mismo patrón anterior (figura 8).

Cuando se analiza si existen linajes militares masculinos entre las mujeres de la Aviación del Ejército, se registra que no hay relación cuando un padre o hermano pertenece o ha pertenecido a las Fuerzas Armadas (Prueba de Fisher: 10.543 y p: 0.090). Similar situación se presenta cuando se analiza la pertenencia del padre y algún tío o tía a las Fuerzas Armadas (Prueba de Fisher: 10.911 y p: 0.083). En la asociación entre abuelos y tío/tía, sí hay una significancia estadística (Prueba de Fisher: 12.076 y p: 0.020), por lo tanto, para el caso de las mujeres de la Aviación del Ejército, el linaje familiar militar masculino lo constituye la participación de los abuelos y los tíos o tías. 
Ahora bien, para el caso de los linajes militares masculinos-femeninos (en los que se incluyen las madres), se encuentra que existe relación significativa entre abuelos y madres pertenecientes a las Fuerzas Armadas (Prueba de Fisher: 16.176 y p: 0.019); de igual manera sucede cuando se pregunta por la relación entre tíos/ tías y madres (Prueba de Fisher: 17.622 y p:0.004). Para el caso de hermanos y sus madres, se encuentra que no existe dependencia entre las variables (Prueba de Fisher: 11.443 y p: 0.122). Por último, existe una gran asociación entre padres y madres pertenecientes a las Fuerzas Armadas ( $\chi^{2}: 64.344$ y p: 0.000), lo que indica, por una parte, que los padres y madres de las mujeres militares se conocen en un ambiente militar, tal como ocurre con las mujeres militares encuestadas; y por otra, que los linajes militares de las mujeres de la Aviación del Ejército se encuentran relacionados de forma muy fuerte cuando existe una adscripción de ambos padres a las Fuerzas Armadas.

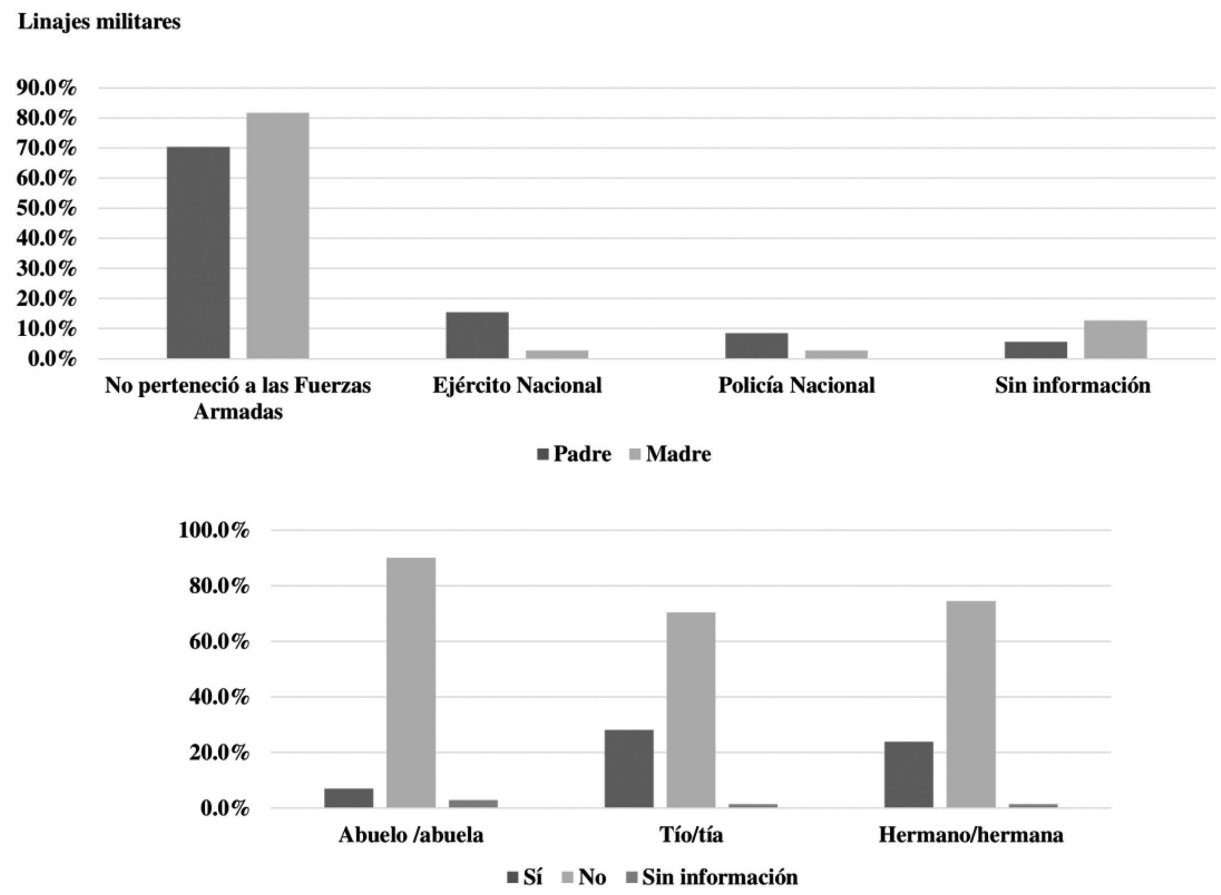

Figura 8. Linajes militares. Pertenencia de padres y madres a las Fuerzas Armadas y pertenencia de abuelo/abuela, tío/tía o hermano/hermana

Fuente: Elaboración propia

Siendo el caso, ya que no existe una gran tradición militar, en muchas ocasiones la pertenencia a la institución es por vocación. Asimismo, se ha detectado que con 
frecuencia entran en juego factores de oportunidad laboral, y también porque pese a ciertos estereotipos que se tienen de la participación en las filas, socialmente está bien visto la pertenencia a una institución como el Ejército (Báez Mediano, 2013).

\section{Valores e identidad: mujeres que se sitúan entre la tradición y la modernidad}

Con respecto a las transformaciones de la composición de la familia, el siglo $\mathrm{XX}$ se identificó con lo inestable y efímero en comparación con la permanencia y estabilidad de creencias y significados de generaciones anteriores. Para este caso, los valores son creencias prescriptivas que indican qué es adecuado o no realizar, son bastante estables, se interiorizan durante el proceso de socialización y forman la base del autoconcepto personal. Por ello son primordiales en la construcción de la identidad, porque a nivel personal, los valores guían nuestras decisiones vocacionales y ocupacionales; mientras que a nivel cultural, los valores guían el accionar de diferentes instituciones que componen la sociedad.

Así, los valores son útiles en dos aspectos básicos. A nivel individual, dan una importante información sobre los comportamientos, actitudes e identidades de las personas, pues son el constructo moral que orienta sus acciones. A nivel cultural, en cambio, los valores son tomados como variables dependientes, resultantes de factores políticos, sociales o económicos (Casullo \& Castro, 2004).

En la perspectiva de la confluencia de un mundo militar (entendido como un mundo de valores), el Ejército busca reconvertir su identidad institucional sin modificar una dimensión sobre la cual ha intentado construir su legitimidad pública: la dimensión moral de la profesión militar (Badaró, 2006). Es evidente la amplia tendencia de los integrantes de las instituciones castrenses a autodefinirse como respetuosos de la moral de la familia (Berrío, 1997); así como a enaltecer otros valores esenciales de la institución militar, como el respeto de los símbolos patrios (la bandera, el escudo y el himno nacional), el respeto a la dignidad de la persona, el fomento de la igualdad de género, la prevención de la violencia de género, el espíritu militar, el honor, el valor, la justicia, el fomento de las tradiciones, el liderazgo, la responsabilidad, el aprecio por la vida de los subordinados y el respeto y colaboración con la población civil, entre muchos otros (Báez Mediano, 2013).

Ya que las estructuras ideológicas se debaten entre la permanencia y la transformación, esta tensión constante permite comprender mejor los comportamientos dentro de un grupo humano: dicha tensión se produce en función de la interpretación y valoración de preceptos políticos, dominancia social, 
prejuicios y temas morales (Corcione Nieto \& Cabrera-Cabrera, 2018). La idea de ciudadano-soldado se ha establecido como una idea en masculino, es por ello que termina siendo imprescindible conocer cómo, a partir de la aprobación o no de derechos civiles y fundamentales y de movimientos sociales (figuras 9 y 10), se va formando la manera de ver o entender ciertas actitudes o formas de comportamiento de las mujeres de la Aviación del Ejército Nacional.

De acuerdo con Casullo y Castro (2004), los valores que se inscriben entre los civiles (quienes se perciben a sí mismos mucho más abiertos a nuevas experiencias) están más orientados hacia el pensamiento independiente, la libertad, el placer y la gratificación, pero menos hacia el respeto y el compromiso con las costumbres e ideas proporcionadas por la cultura, en comparación con los militares. Estos últimos, están más dispuestos a aceptar lo establecido.

En cuanto a la pena de muerte, el 74,6\% de las encuestadas están de acuerdo, mientras que el 16,9\% está en desacuerdo y el 8,5\% es indiferente al tema (figura 9). Además, el $67,6 \%$ de las mujeres está de acuerdo con la eutanasia, mientras que el $22,5 \%$ está en desacuerdo y el 9,9\% es indiferente (figura 9). En cuanto a la libertad sexual, el 60,6\% de las mujeres del arma de Aviación está de acuerdo, el 19,7\% está en desacuerdo y el mismo porcentaje es indiferente al tema (figura 9). Más de la mitad de las mujeres encuestadas está en desacuerdo con la prostitución (57,7\%), el 36,6\% es indiferente al tema y solo un 5,6\% está de acuerdo (figura 9).

También se indagó en cuanto al derecho a la libertad sexual, que abarca todos y cada uno de los derechos sexuales y reproductivos, y que se centra en la posibilidad de ejercer la sexualidad de manera responsable (Zárate Angarita, 2014). Este derecho se materializa a través de las decisiones personales como máxima expresión de la libertad individual y ciudadana en los contextos laicos (Ministerio de Salud y Protección Social, 2015a). Al buscar si existía relación entre las variables asociadas a la religión y el ejercicio de este derecho, no se encontró una correspondencia significativa, tanto en la existencia de un ambiente familiar religioso en las familias de las mujeres de Aviación (Prueba de Fisher: 4.592 y p: 0.342) como en el caso de que ellas se consideren practicantes de alguna religión (Prueba de Fisher: 2.883 y p: 0.656).

Por consiguiente, las mujeres del arma de Aviación se vinculan a valores modernos, que están inscritos en el cambio que tuvo la mujer a inicios del siglo XX. Estas empezaron a separarse del respaldo de la fe católica al patriarcalismo, cuestionaron y desobedecieron sus principios en su lucha por la equiparación de los géneros, desoyeron los fundamentos morales contra el aborto, el divorcio, la reincidencia nupcial y el control natal, entre otros. Así, los conceptos de pecado sexual, virginidad, castidad prematrimonial y fidelidad marital se revaluaron y se expandió, en su lugar, el derecho de la mujer al placer sexual (Gutiérrez de Pineda, 2005). 
Al contrario de lo anterior, la alta desaprobación de la prostitución y, aún más importante, el gran porcentaje de mujeres militares para quienes esto les es indiferente, presenta un desafío en su comprensión. Además, al igual que para el derecho a la libertad sexual, no hay asociación estadística entre ambientes familiares religiosos (Prueba de Fisher: 4.194 y p: 0.380) y considerarse una persona religiosa (Prueba de Fisher: 2.168 y p: 0.904), por tanto, podría pensarse que la desaprobación no se presenta por una cuestión moral. Esta propuesta se apoya en que tampoco existe relación entre pertenecer a una familia tradicional o moderna y la aprobación de la prostitución (Prueba de Fisher: 1.312 y p: 0.513).

De esa manera se puede problematizar si la desaprobación se presenta en los límites de la legalidad o ilegalidad en el ejercicio del trabajo sexual o, por el contrario, se encuentra en la disputa de la dominación de género tras el fenómeno de la prostitución. En Colombia, la prostitución no es ilegal, no está penalizada, como se admite en la sentencia T-629 de 2010, pero tampoco hay un marco jurídico específico que proteja los derechos y regule el oficio de las personas que ejercen la prostitución voluntariamente (“¿Se podrá regular la prostitución en Colombia?”, 2015). Esta situación, más que una adscripción moral o feminista respecto del trabajo sexual, puede ser la causa de la alta desaprobación por parte de las mujeres militares.
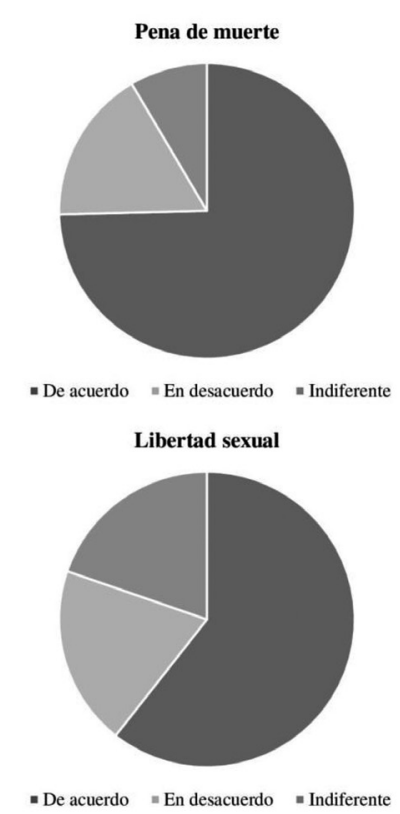
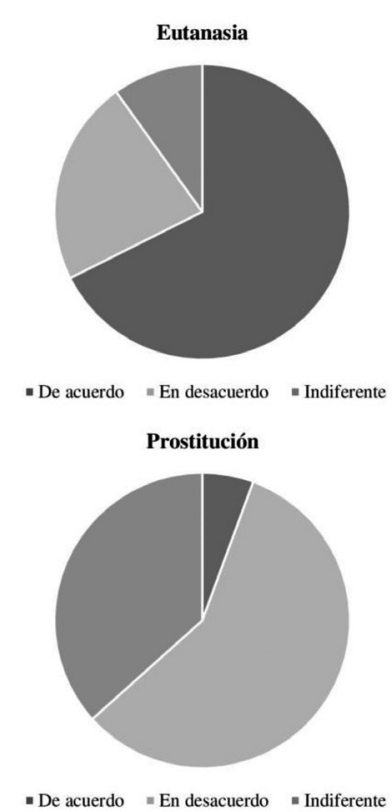

Figura 9. Opinión de las mujeres de la Aviación del Ejército Nacional sobre temas relacionados con valores morales.

Fuente: Elaboración propia 
La pena de muerte no está legalizada en el país, y la eutanasia, aunque está reglamentada, solo puede ser solicitada en algunos casos. Ambas prácticas implican cuestiones morales derivadas de tener que quitar la vida a otro ser humano. Con esto en mente, se buscó establecer si existía relación entre la adscripción a alguna religión y la eutanasia, pero no se encontró significancia estadística (Prueba de Fisher: 3.910 y p: 0.434); de igual manera sucedió cuando se planteó la relación entre practicar alguna religión y la pena de muerte (Prueba de Fisher: 2.665 y p: 0.827). Cuando se indagó sobre la relación entre el ambiente religioso de la casa y la eutanasia, también se encontró independencia de las variables (Prueba de Fisher: 4.677 y p: 0.304); lo mismo sucedió en cuanto a la pena de muerte (Prueba de Fisher: 1.106 y p: 0.941).

Sin que la aprobación de la pena de muerte por parte de las mujeres encuestadas sea un asunto moral o religioso, se encontró que puede estar ligada a la idea del castigo judicial, basado en la inseguridad, el ascenso de la delincuencia, el avance del secuestro, las violaciones sexuales y el terrorismo, fenómenos que aumentan cada vez más en América Latina y en Colombia (Aguilera, 1995), ante la inoperancia de la justicia que se traduce en impunidad (Corcione Nieto et al., 2019).

Porcentajes similares a los presentados entre las mujeres militares se observan en la población colombiana cuando se pregunta por la pena de muerte. El 76,8 \% de las personas se muestra a favor de esta, mientras que el 23,2 \% afirma no estar de acuerdo ("Bumangueses opinan sobre pena muerte, eutanasia y castración", 2017). Según el periódico El Tiempo, ante la consulta de la pena de muerte para secuestradores,

Numerosos oficiales de alto rango del Ejército y la Policía se mostraron de acuerdo con la posibilidad de instaurar la pena de muerte en el país porque consideraron que el secuestro es un delito extremadamente grave. De manera unánime, los miembros de las FF.AA. consultados por este diario coincidieron en que la sanción máxima haría que los secuestradores pensaran dos veces antes de involucrarse en la empresa de retener a una persona con fines extorsivos. Otro oficial del Ejército sostuvo que la pena de muerte produciría una reacción inmediata de la población, que empezaría a delatar a los delincuentes. ("Pena de muerte: sí o no", 1992)

De igual manera, la eutanasia es un tema de gran discusión en Colombia, pues no es fácil puntualizar sobre ella. El desconocimiento general que se tiene y el hecho de tratar directamente con la muerte presenta uno de sus más graves problemas, ya que en muchos sectores se piensa que con su práctica se vulneran de una u otra forma los principios morales de cada persona y sus creencias religiosas (Delgado Rojas, 2017). Aunque (como se estableció anteriormente) no existe asociación entre 
las creencias religiosas de las mujeres militares y la aprobación o desaprobación de la eutanasia, al momento de realizar encuestas a la población se encuentra que el $73 \%$ de los colombianos aprueban la eutanasia ("El $73 \%$ de los colombianos cree que la eutanasia debe ser legal”, 2015), cifra similar a lo que se observa entre las mujeres de la Aviación. Esta paradoja puede deberse a que la aprobación se establece a partir de la concepción de la eutanasia como mecanismo legal para acabar con el sufrimiento de una persona que padezca enfermedades terminales y que de manera voluntaria quieran acabar con ese dolor ("El $73 \%$ de los colombianos cree que la eutanasia debe ser legal”, 2015), concepción que permite aceptar el mecanismo legal de la eutanasia gracias a una concepción moral diferente. Es así como se permite esa dualidad con la muerte: la muerte para aliviar sufrimiento (en el caso de la eutanasia) o para castigar acciones deplorables (por medio de la pena de muerte).

En cuanto a los movimientos sociales, se observa que el 15,5\% de las mujeres encuestadas apoyan bastante a los movimientos provida (en contra del aborto), mientras que el $38 \%$ apoyan el derecho al aborto (figura 10). Por su parte el 25,4\% de las mujeres apoya poco este derecho, y el $21,1 \%$ no lo apoya para nada (figura 10). En cuanto a los movimientos feministas, el $15,5 \%$ de las mujeres los apoya bastante, el 4,2\% mucho, el 26,8\% nada y la mayoría de mujeres apoyan poco los movimientos feministas (53,5\%) (figura 10).
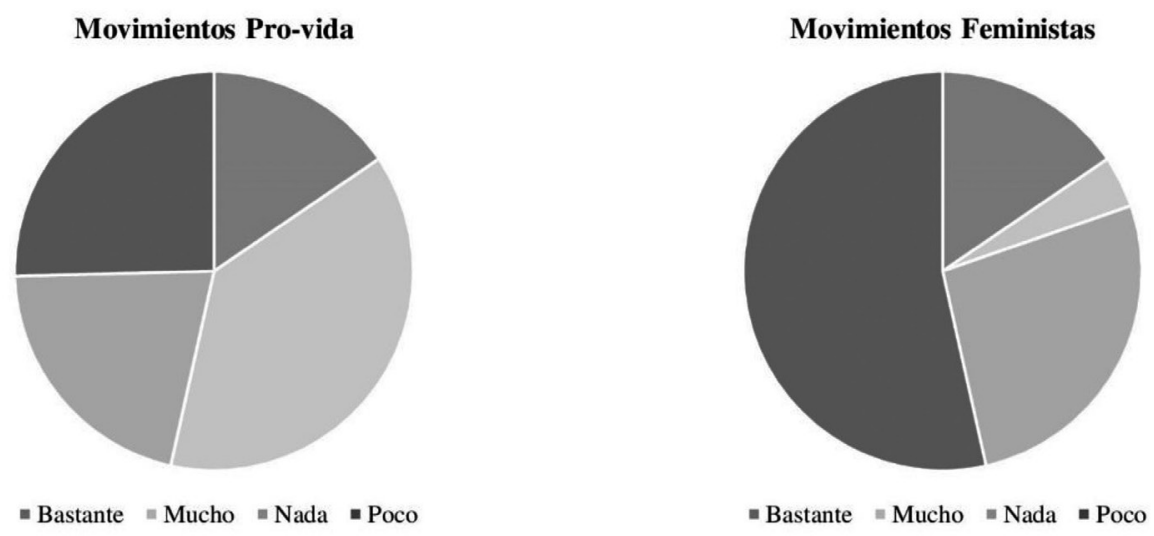

Figura 10. Opinión de las mujeres de la Aviación sobre la aprobación de movimientos sociales feministas y provida.

Fuente: Elaboración propia

En casi todos los países, el surgimiento de grupos provida se desarrolla de forma paralela a los intentos de sancionar la legalidad del aborto por el poder polí- 
tico. El aborto es quizá el elemento transversal que más controversia política ha representado y representa hoy en día en el mundo. Así, al tiempo que en muchos países se aprobaban leyes abortistas, en muchos otros se blindaba el ideario provida (Pérez Adán et al., 2010). Esta controversia es evidente en los porcentajes de aprobación del aborto en el país. En 2015, el $55 \%$ de los participantes en la encuesta de percepción estuvo de acuerdo con el aborto en ciertas condiciones (Ministerio de Salud y Protección Social, 2015b), y para el 2017 el porcentaje de colombianos aumentó al $65 \%$ a favor del aborto en ciertas condiciones (Rubiano, 2017). Sin embargo, las mujeres de la Aviación del Ejército son más renuentes a apoyar el derecho al aborto.

Nuevamente la percepción de la muerte y su multiplicidad de significados (quién la merece y quién no) juega un papel trascendental; al igual que para la eutanasia, para los movimientos provida no existe una asociación estadísticamente significativa entre las creencias religiosas de las mujeres encuestadas (Prueba de Fisher: 5.221 y p: 0.534) y el ambiente religioso de sus familias (Prueba de Fisher: 4.378 y p: 0.651 ). No se presenta tampoco una asociación significativa entre las familias modernas y tradicionales y los movimientos provida (Prueba de Fisher: 3.098 y p: 0.396).

Por ello, reducir el debate a una supuesta inconsistencia moral es dejar de lado la multiplicidad de facetas que el aborto implica para las mujeres. Aunque el mundo se ha modernizado y las concepciones e intenciones políticas, filosóficas y morales de estas posiciones también han evolucionado, siempre seguirá presentándose el debate público (el rechazo del aborto por parte de grupos provida) y la interiorización del ámbito privado y personal, que llevan a plantearse interrogantes acerca de la práctica del aborto desde la propia experiencia. Sin que sea de interés para esta investigación profundizar en estos debates de lo público y lo privado a partir de la propia experiencia femenina, se plantea aquí la multidimensionalidad que representa el apoyar o no los movimientos provida.

De igual manera podría resultar paradójico que entre las mujeres militares no exista un gran apoyo a los movimientos feministas. No obstante, tradicionalmente se ha confundido la valoración de las actitudes hacia los roles de género con las actitudes feministas (Yago Alonso \& Paterna Bleda, 2005). Conforme a una encuesta realizada a mujeres en el Reino Unido (Scharff, 2019), las personas no parecen rechazar el término feminismo porque estén en contra de la igualdad de género o porque crean que se ha logrado; más bien, creen que el término no les representa. Para el caso de las mujeres de la clase trabajadora, el término feminista no las atrae, pero sí creen que hombres y mujeres deben ser iguales en todos los aspectos. Esto 
puede sugerir que, al igual que la tendencia de mujeres en el mundo, el grupo de mujeres entrevistadas del Ejército Nacional respaldan la igualdad que sustenta la idea del feminismo, pero no están interesadas en la palabra en sí.

Los movimientos sociales surgen, entre otros factores, porque hay grupos de personas no satisfechas o no convencidas del nuevo orden social, ni con su organización ni con las políticas sociales diseñadas para paliar los conflictos (Álvarez Domínguez \& Yanes Cabrera, 2011). Ante esta situación, desligarse de los movimientos feministas, permite darse cuenta que para estas mujeres no es importante cuestionarse el orden social. Es por ello que

el análisis de la identificación con ciertas categorías sociales basadas en parámetros relacionales, vocacionales, étnicos, religiosos, de estigma social o de afiliación ideológico-política proporciona una base para la reflexión sobre las múltiples intersecciones que confluyen en la categoría social mujer, y una aportación al debate sobre el género. (Yago Alonso \& Paterna Bleda, 2005)

\section{Discusión}

Pensar a las mujeres en un contexto histórico y cultural concreto permite, por un lado, adentrarse en una política de identidad, una política de nosotras versus los otros, para luego hacer la transición a una política en la que se contextualice la experiencia vivida. En el caso aquí presentado, resulta primordial exponer los cuestionamientos básicos sobre cómo se construye un nosotras (mujeres militares del arma de Aviación del Ejército) a partir de las experiencias femeninas en la configuración de sus identidades en un ambiente hegemónicamente masculino y patriarcal. Por ello fue fundamental explorar la categoría de experiencia, poniéndola en tensión con categorías como identidad, diferencia y representación, que permiten distinguir entre mujeres en tanto sujetos históricos, frente a una mera imagen de mujer. Así como no hay una única cultura, las mujeres tampoco están unificadas en una única posición ante la diversidad de opciones.

En esa construcción de identidad femenina se vinculan y desvinculan, en una tensión permanente, las experiencias femeninas antes y durante la participación en una carrera militar, así como en la construcción de una mujer-soldado en el Ejército Nacional. De esta manera, podemos decir que la identidad tiene unos límites difusos que se dilatan y cambian tanto desde el punto de vista individual, como desde el punto de vista colectivo dependiendo de los contextos en que se presenten. Para el caso de la configuración de la identidad femenina, esta se ve sujeta a múltiples cambios y adaptaciones que conforman una amalgama iden- 
titaria (que rara vez se presenta entre los hombres) que se conjuga en términos de poder y feminidad. Es por ello que se hace imperativo el carácter semiótico y discursivo de la realidad propia, que subraya el valor construido y representacional de las marcas de identidad masculina y femenina impuestas sobre los cuerpos de hombre y de mujer (Richard, 1996).

Esta disputa en la configuración femenina se inicia con la incursión de la mujer en el mercado laboral y sus repercusiones en la cognición social en términos de expectativas en función del género, que están aún muy vinculadas a los espacios de empleo femenino y que se concentran en ocupaciones feminizadas. Para el caso de las mujeres que se ubican en esferas no tradicionales, esto supone una ruptura del ideal estereotipado que las instala en un sospechoso lugar de trasgresión, lo cual funciona como una fuente de represión social y psicológica que les impulsa a mantenerse dentro de los parámetros del statu quo (Martínez Herrera, 2007).

Esta transgresión está reforzada por la visión tradicional de la carrera militar, dominada por imágenes masculinas. La institución castrense se conforma hacia el interior como un grupo cerrado con su propia cultura y se muestra al exterior como poseedora de una identidad propia (Báez Mediano, 2013). Dentro de ella, el género, como etiqueta social que usan los individuos de manera instantánea y sistemática para ser encasillados, tiene una influencia más marcada. Como lo exponen Facio y Fries (2005), los espacios patriarcales no solo afectan a las mujeres al ubicarlas en un plano de inferioridad en la mayoría de los ámbitos de la vida, sino que restringen y limitan a los hombres, a pesar de su situación de privilegio al asignar a las mujeres un conjunto de características, comportamientos y roles propios de su sexo. Por consiguiente, los hombres muchas veces prescinden de estos roles, comportamientos y características. Como resultado de esta dinámica, la transgresión femenina se desvanece y la identidad de las mujeres vuelve a entrar en tensión.

La incorporación y progreso de mujeres en las filas armadas choca con las imágenes heroicas del profesional militar que continúan imperando y que constituyen muchas veces un cliché (Donadio, 2010). Esto hace que la visibilización de una minoría femenina quede atrapada en el estereotipo de la noción de mujer como ficción, producida por los discursos hegemónicos, entre ellos, el militar. Aunque en la actualidad las mujeres en diversos ejércitos del mundo pueden acceder a cualquier cuerpo de armas y no existen cuotas limitadoras de su acceso, ellas siguen siendo una minoría entre las filas. Como resultado, se puede observar que las mujeres pertenecientes a la Aviación del Ejército, al ser un grupo tan pequeño distribuido en muchas unidades a lo largo del país, está expuesto de forma más fácil al estereotipo. 
La institución castrense vuelve invisibles a las mujeres, excepto que ocasionalmente las muestra como símbolos desde el tokenismo.

Es bien sabido que los estereotipos generan expectativas de comportamiento. Ante esta presión que sufren las mujeres por encajar en una institución masculinizada, en muchos casos se ha podido contemplar que estas adoptan estrategias que se enfocan en sus identidades como soldados, distanciándose muchas veces de otras mujeres para demostrar su capacidad para competir con los hombres, mientras mantienen prácticas femeninas en situaciones sociales (Doan \& Portillo, 2017).

La profesión militar es una vocación de servicio a la patria que encierra varias normas de comportamiento, experiencias, conocimientos especializados, habilidades y virtudes morales que le ayudan al militar a dar todo, hasta la vida misma si es necesario. A raíz de esto, se aprecia como una profesión de mucho compromiso, donde es importante además contar con una importante formación física, psicológica, intelectual y moral (González, 2015). Su ejercicio implica la formación de una mentalidad determinada.

Además, la vinculación individual a una institución como la castrense genera una identidad colectiva que se relaciona con el autosacrificio de sus miembros en nombre de intereses superiores; elemento primordial que los separa de otros grupos humanos. La abnegación, el desinterés, el honor, la disciplina y el renunciamiento de esta vinculación implican una remuneración inferior a la que se percibiría en el mercado. Esto se compensa con la percepción de estar cumpliendo un deber superior al que cumple cualquier profesional (Fontana, 2005, p. 9).

A esta configuración de la vocación de la carrera militar se adiciona para las mujeres ya no esferas del liderazgo heroico (reservado para los hombres), sino atributos de entrega, sacrificio y servicio a los demás, que se asocian con el rol tradicional femenino. De igual forma, se hace siempre una exaltación inusitada de la noble función de la madre y del valor de la maternidad, ya sea para resaltar el sacrificio en la relación entre la familia y el Ejército o para transformarla como comunidades morales complementarias, entendidas como identidades colectivas particulares. Sobre las mujeres militares se resalta siempre la disputa que existe en la conciliación entre la vida profesional, personal y familiar de los miembros de las Fuerzas Militares.

A pesar de esto, las mujeres que integran el arma de la Aviación del Ejército comparten la condición de la mayoría de mujeres de la sociedad civil. Esto se desprende de la forma en que las relaciones de los roles masculinos y femeninos se han desarrollado en diversos ámbitos sociales. Al igual que los oficiales modernos, ellas no constituyen un cuerpo separado de la sociedad civil, sino que se encuentran 
profundamente integradas a esta (Janowitz, 1960). No hay que olvidarse de que las Fuerzas Militares y el Ejército deben entenderse como organizaciones que, mientras mantienen ciertos niveles de autonomía y configuración cerrada, reflejan también amplias tendencias sociales.

Además, están presentes las variaciones que se han establecido en el reclutamiento de oficiales y de tropa: las motivaciones para el ingreso a la carrera ya no expresan el predominio de la herencia familiar, la proveniencia de determinado tipo de familia o la búsqueda de preeminencia social (Donadio, 2010). En este sentido, cada integrante (hombre y mujer) del Ejército encaja en un grupo humano específico dentro de la institución. Para el caso de la Aviación del Ejército, se tiene un asunto particular, pues se trata de un soldado formado con los mismos principios, valores e identidad que las tropas en tierra, ya que se instruyó y adquirió las convenciones propias del personal del Ejército, lo que lo convierte en un soldado de tierra (Urrego, 2019).

Por consiguiente, la dinámica de construcción de identidad femenina, como se demostró en los resultados, no es única, fija ni lineal. Es posible, en efecto, aceptar que la categoría de lo femenino es producida por una multiplicidad de formas culturales que provocan efectos diversificados al instituir prácticas dominantes (González, 2015). Nuevamente, las mujeres militares se convierten en transgresoras. Para la sociedad en general, estas se vinculan a los contraestereotipos, rompiendo la pacífica y aceptada apariencia para construir nuevas formas sociales y, en muchos casos, para comenzar nuevos modelos que poco a poco van siendo aceptados por la sociedad (Bernad et al., 2013).

Despojar sus prácticas de lo militar implica también despojarlas a ellas de sus particularidades: "identificarse con alguna colectividad es dar prioridad a una identificación determinada sobre todas las demás, puesto que en la práctica todos somos seres multidimensionales" (Hobsbawm, 1993, p. 54). Esta multidimensionalidad en la construcción de las identidades enmarca la opinión sobre las actitudes de otros y, más importante aún, arroja visiones sobre la historia y el devenir.

\section{Conclusiones}

Comprender la conformación de un grupo minoritario dentro de lo hegemónico masculino no es tarea fácil, ya que se debe partir de la deslegitimación de las figuras estereotipadas existentes. Para ello, uno de los caminos es el análisis de la conformación de la identidad. Debido a que las personas se componen como sujetos sociales a través de los significados, hábitos y disposiciones que operan en la 
sociedad en la que están insertos, se ha hecho crucial darle una mirada a las mujeres que integran el arma de Aviación del Ejército Nacional de Colombia.

Según los idearios esencialistas femeninos, se ha constituido un imaginario social por medio de patrones que encasillan a las mujeres militares desde la naturaleza de su servicio. Es por ello que desde las dimensiones de la experiencia femenina, se muestra una nueva posición identitaria femenina militar que se desliga de la imagen estereotipada. La individualidad da cuenta solo hasta cierto punto de lo social, en tanto lo social explica, solo en parte, el acontecer individual.

Las mujeres que integran el arma de Aviación del Ejército son un grupo heterogéneo, cuya identidad se estructura por medio de la experiencia femenina, la cual está limitada por las exigencias de la vida militar y su fuerte tendencia al establecimiento binario de roles contradictorios pero complementarios. El carácter cambiante y multidimensional del establecimiento de la identidad muestra en estas mujeres las tendencias del mundo femenino de la sociedad civil: la soltería como una forma de reducir la presión que ejerce el mundo laboral y la aceptación del cuidado como rol femenino impuesto. La complejidad de la construcción de la identidad militar y del espíritu de cuerpo entre las mujeres militares se percibe en la interacción de valores tradicionales y de permanencia que no interpelan el orden social establecido.

Siempre es importante recordar que la integración de las mujeres a las filas del Ejército Nacional debe ser vista como un proceso bidireccional en constante desarrollo y de ajuste mutuo por parte de todos los implicados. Por tanto, los cambios que se presentan en un ambiente de adaptación contextual son dinámicos y deben estar en constante análisis. La manera en que se presenten las mujeres militares permitirá la aparición de modelos femeninos que se desligan del estereotipo y supongan una fuente de inspiración para mujeres con vocación para la vida militar en el futuro. Por el momento, no se trata de tener muchas mujeres en la tropa, se trata de empoderar a las mujeres que pertenecen al Ejército y desligarlas de las imágenes y los roles estereotipados.

\section{Referencias}

Aguado, M. A., \& Portal, J. C. (1991). Tiempo, espacio e identidad social. Alteridades, 1(2), 31-41. Aguilera, M. (1995). La pena de muerte. Una propuesta constante. Análisis Político, 26, 3-17. https:// revistas.unal.edu.co/index.php/anpol/article/view/76032/68486

Alejo Jara, M. A., \& Columé Alonso, A. (2016). Debatiendo lo femenino. Políticas, cultura y educación. En C. García Gil, C. Flecha García, M. J. Cala Carrillo, M. Núńez Gil, \& A. Gil Bozal 
(Coords.), Mujeres e investigación. Aportaciones interdisciplinares. VI Congreso Universitario Internacional "Investigación y Género". Universidad de Sevilla.

Alexiévich, S. (2015). La guerra no tiene rostro de mujer. Debate.

Alioni, A. C. (2016). Reflexiones acerca del carácter de la incorporación de mujeres a la institución militar en Argentina [Ponencia]. Mujeres e investigación. Aportaciones interdisciplinares. VI Congreso Universitario Internacional Investigación y Género (9-21), Sevilla; Siemus (Seminario Interdisciplinar de Estudios de las Mujeres de la Universidad de Sevilla). https://idus.us.es/ handle/11441/51012

Almeida Sanguinet, N. (2015). La mujer armada: la incorporación de la mujer en el Cuerpo de Oficiales de la Armada Nacional. Un estudio normativo [Trabajo de grado]. Universidad de la República, Uruguay.

Álvarez Domínguez, P., \& Yanes Cabrera, C. (2011). Derechos humanos y movimientos sociales: experiencia participativa en la universidad. Revista de Estudios y Experiencias en Educación, 10(19), 153-175.

Atehortúa, A. (2004). Los estudios acerca de las Fuerzas Armadas en Colombia: balance y desafío. Análisis Político, 51, 12-24.

Badaró, M. (2006). Identidad individual y valores morales en la socialización de los futuros oficiales del ejército argentino. Avá. Revista de Antropología, 9, 60-76.

Báez Mediano, A. (2013). Por los senderos de palas: etnografía sobre la incorporación de la mujer a la institución militar [Trabajo de maestría, Universidad de Salamanca]. https://gredos.usal.es/ bitstream/handle/10366/123308/TFG_BaezMediano_Senderos.pdf?sequence=1\&isAllowed=y

Bazo, M. T. (2008). Personas mayores y solidaridad familiar. Politica y Sociedad, 45(2), p. 73-85

Becerra Elejalde, L. (2019, noviembre 11). El DANE informó que población que se reconoce afro asciende a 2,98 millones de personas. La República. https://www.larepublica.co/economia/ el-dane-informo-que-la-poblacion-afro-asciende-a-298-millones-de-personas-2929745

Beck, U., \& Beck-Gernsheim, E. (2001). El normal caos del amor: las nuevas formas de la relación amorosa. Paidós.

Bernad, E., Mut, M., \& Fernández, C. (2013). Estereotipos y contraestereotipos del papel de la mujer en la Gran Guerra. Experiencias femeninas y su reflejo en el cine. Historia y Comunicación Social, 18, 169-189. http://dx.doi.org/10.5209/rev_HICS.2013.v18.43421

Berrío, F. J. (1997).Valores institucionales de las Fuerzas Armadas. Cuadernos de Estrategia, 89, 127-170. https://dialnet.unirioja.es/servlet/articulo?codigo $=2781427$

Bobea, L. (2003). Entre el escudo de Minerva y el manto de Penélope: la feminización del servicio militar en el Caribe, una práctica dicotomizada. Resdal.org. https://bit.ly/3mVXs54

Bobea, L. (2008). Mujeres en uniforme: la feminización de las fuerzas armadas. Un estudio del caso dominicano. Nueva Sociedad, 213, 64-79.

Borreguero Beltrán, C. (2016). La historia militar en el contexto de las nuevas corrientes historiográficas. Una aproximación. Manuscrits. Revista d'Història Moderna, 34, 145-176. https://doi. org $/ 10.5565 / \mathrm{rev} / \mathrm{manuscrits} .87$

Bumangueses opinan sobre pena muerte, eutanasia y castración. (2017, junio 25). Vanguardia. https:// www.vanguardia.com/area-metropolitana/bucaramanga/bumangueses-opinan-sobre-pena-muerte-eutanasia-y-castracion-jfvl401697 
Burk, J. (2002). Morris Janowitz y los orígenes de la investigación sociológica sobre las fuerzas armadas y la sociedad. Security and Defense Studies Review, 2, 126-142.

Butler, J. (1990). Gender trouble: Feminism and the subversion of identity. Routledge; Chapman and Hall.

Castañeda Rentería, L. I. (2019). ¿`Nuevas sujetas, nuevas identidades? La vivencia profesional en la configuración de la identidad de género. Noesis, Revista de Ciencias Sociales y Humanidades, 28(55), 90-108. http://dx.doi.org/10.20983/noesis.2019.1.5

Casullo, M. M., \& Castro, A. (2004). Valores humanos y contextos en población civil y militar. Acción Psicológica, 3(1), 21-30.

Collazos, M. (2020, mayo 19). Por cada 100 matrimonios se han registrado 41 divorcios en los últimos tres años en Colombia. RCN Radio. https://www.rcnradio.com/colombia/por-cada-100-matrimonios-se-han-registrado-41-divorcios-en-los-ultimos-tres-anos-en

Colombia, primero en Latinoamérica en nuevos tipos de familia. (2016, marzo 20). El Heraldo. https://www.elheraldo.co/tendencias/colombia-el-hogar-de-las-nuevas-familias-249788

Colombianas están postergando la edad para ser madres: Dane. (2019). El Heraldo. https://www. elheraldo.co/colombia/colombianas-estan-postergando-la-edad-para-ser-madres-dane-640299

Colombo, M., \& Patitucci, J. (2016). Las relaciones amorosas como fenómeno empresarial. [Trabajo final de investigación]. Repositorio de la Universidad Argentina de la Empresa. https://repositorio. uade.edu.ar/xmlui/bitstream/handle/123456789/5047/COLOMBO\%20-\%20TIF.pdf?sequence $=1$ \&isAllowed $=y$

Colotta, M. (2013). Reflexiones preliminares y diagnóstico en torno a perfiles, imaginarios, percepciones y expectativas de los aspirantes a oficiales del primer y último año del Colegio Militar de la Nación, Escuela de aviación militar y Escuela Naval (2012) [Ponencia]. X Jornadas de Sociología. Universidad de Buenos Aires, Buenos Aires. http://www.aacademica.org/000-038/252

¿Cómo es la nueva familia colombiana? (2012). Revista Credencial. http://www.revistacredencial.com/ credencial/noticia/actualidad/como-es-la-nueva-familia-colombiana

Corcione Nieto, M. A., \& Cabrera-Cabrera, L. J. (2018). Identidad e ideología. Dinámicas culturales entre los estudiantes de la Escuela Militar de Cadetes. En A. Fernández Osorio, \& E. Latorre Rojas (Eds.), La construcción del rol de la mujer militar (pp. 41-65). Escuela Militar de Cadetes "General José María Córdova”.

Corcione Nieto, M. A., Fernández-Osorio, A. E., Cabrera-Cabrera, L. J., \& Rojas Yaima, B. C. (2019). Aportes de la Academia a la legitimidad de la justicia en Colombia. Revista Cientifica General José María Córdova, 17(28), 819-843. https://doi.org/10.21830/19006586.516

DANE. (2005). Censo General 2005. Nivel Nacional. https://www.dane.gov.co/files/censos/libroCenso2005nacional.pdf

De Angelis, K., \& Segal, M. W. (2015). Transitions in the military and the family as greedy institutions: original concept and current applicability. En R. Moelker, M. Andres, G. Bowen, \& P. Manigart (Eds.), Military families and war in $21^{\text {st }}$ century (pp. 22-42). Routledge.

De la Torre Galvis, J. (2013, julio 19). La familia en Colombia está en crisis. Semana. https://www. semana.com/vida-moderna/articulo/la-familia-colombia-esta-crisis/351347-3/

Delgado Rojas, E. J. (2017). Eutanasia en Colombia: una mirada hacia la nueva legislación. Justicia, 31, 226-239. 
Departamento Administrativo Nacional de Estadística [DANE]. (2019). Población indígena en Colombia. Resultados del censo nacional de población y vivienda 2018. https://www.dane.gov.co/ files/investigaciones/boletines/grupos-etnicos/presentacion-grupos-etnicos-2019.pdf

Doan, A., \& Portillo, S. (2017). Not a woman, but a soldier: Exploring identity through translocational Positionality. Sex Roles, 76, 236-249. 10.1007/s11199-016-0661-7

Donadio, M. (2004). La incorporación de la mujer en las fuerzas armadas de la Argentina [Ponencia]. XXV International Congress, Asociación de Estudios Latinoamericanos (LASA), Las Vegas, Nevada, Estados Unidos.

Donadio, M. (2010). La cuestión de género y la profesión militar. En Ministerio de Defensa (Ed.), Género y Fuerzas Armadas: algunos análisis teóricos y prácticos (pp. 51-57). Ministerio de Defensa; Fundación Friederich Ebert. https://docplayer.es/7507230-Genero-y-fuerzas-armadas-algunos-analisis-teoricos-y-practicos.html

Donadio, M. (2018). La perspectiva de género en los ejércitos: misiones y conformación interna. Resdal. org. https://bit.ly/2TVzrOQ

El $73 \%$ de los colombianos cree que la eutanasia debe ser legal. (2015, julio 31). RCN Radio. https:// www.rcnradio.com/colombia/el-73-de-los-colombianos-cree-que-la-eutanasia-debe-ser-legalcolombia-opina

El Ejército tiene a la primera mujer piloto de un helicóptero Black Hawk. (2018, agosto 26). El Espectador. https://www.elespectador.com/noticias/judicial/el-ejercito-tiene-a-la-primera-mujer-piloto-de-un-helicoptero-black-hawk/

Elizalde, S. (2008). Debates sobre la experiencia, un recorrido por la teoría y la praxis feminista. Oficios Terrestres, 23, 18-30.

Facio, A., \& Fries, L. (2005). Feminismo, género y patriarcado. Academia. Revista sobre Enseñanza del Derecho en Buenos Aires, 3(6), 259-294.

Filgueria, B. (2018, julio 28). Cuáles son las causas psicológicas de las relaciones amorosas en el trabajo. Infobae. https://www.infobae.com/tendencias/2018/07/28/cuales-son-las-causas-psicologicas-de-las-relaciones-amorosas-en-el-trabajo/

Fontana, A. (2005). Consideraciones sobre el rol de las fuerzas armadas y la profesión militar [Documento de Trabajo n. ${ }^{\circ}$ 127]. Repositorio de la Universidad de Belgrano. http://repositorio.ub.edu.ar/ handle/123456789/280

Franzway, S. (2000). Women working in a greedy institution: Commitment and emotional labour in the Union Movement. Gender, Work and Organization, 7(4), 258-268.

García Meraz, M., Salvador García, A., \& Guzmán Saldaña, R. (2012). Actitudes hacia la transformación de la vida en pareja: soltería, matrimonio y unión libre. Psicología Iberoamericana, 20(2), 16-25.

García, D., \& Jaramillo, A. (2018, diciembre 10). ¿Por qué se ha reducido el tamaño de los hogares? Razón pública. https://razonpublica.com/por-que-se-ha-reducido-el-tamano-de-los-hogares/

García-Guiu López, C. (2017). Cohesión grupal y espíritu de cuerpo en las unidades de Seguridad y Defensa. Revista de Pensamiento Estratégico y Seguridad CISDE, 2(1), 65-77.

Giménez, G. (1996). La identidad social o el retorno del sujeto en sociología. Versión, 2, 183-205. https:/versionojs.xoc.uam.mx/index.php/version/article/view/24

Golovanevsky, L. (2006). Vulnerabilidad y transimisión intergeneracional de la pobreza, un abordaje cuantitativo para Argentina en el siglo XXI [Tesis doctoral, Universidad de Buenos Aires]. 
Biblioteca Digital de la Facultad de Ciencias de la Universidad de Buenos Aires. http://bibliotecadigital-old.econ.uba.ar/download/tesis/1501-1179_GolovanevskyL.pdf

Gómez, M., Hormigos, J., \& Pérez, R. (2016). Familia y suelo pegajoso en las fuerzas armadas españolas. Revista Mexicana de Sociología, 78(2), 639-663.

González, A. (2015). Consecuencias en la salud psicológica de la instrucción de vuelo: estudio de una muestra de alumnos e instructores militares [Tesis doctoral]. Universidad de Murcia.

Gorlero, M. E. (2020). La soltería femenina: una fuente de sospechas. Revista Movimiento, 24, 23-29.

Gutiérrez de Pineda, V. (2005). Modalidades familiares de fin de siglo. Maguaré, 19, 287-299.

Harrell, M., \& Miller, L. (1997). New opportunities for military women. Effects upon readiness, cohesion, and morale. National Defense Research Institute, RAND.

Hobsbawm, E. (1993). La crisis de las ideologías actuales. Cuenta y razón, 82-83, 15-26.

Janowitz, M. (1990). El soldado profesional. Ministerio de Defensa de Espańa.

King, M. (2014). Las mujeres en combate. La mujer soldado. Military Review. https://www.armyupress.army.mil/Portals/7/military-review/Archives/Spanish/MilitaryReview_20140430_ art006SPA.pdf

López, C. (2018, febrero 22). Sigue en crecimiento: en Colombia 6 de cada 10 mujeres son madres solteras. Canal Uno. https://canal1.com.co/entretenimiento/sigue-en-crecimiento-en-colombia-6-de-cada-10-mujeres-son-madres-solteras/

López, Y. (2003). La familia como capo de saber de las ciencias sociales. Revista de Trabajo Social, 5, 25-40.

Lucero, M. R. (2009). Las mujeres en las fuerzas armadas argentinas. Breve análisis sobre su participación y estado actual de la situación. Unisci Discussion Papers, 20, 36-49.

Malamud, M. (2013). Sociología militar. Boletín del Centro Naval, 837, 384-388.

Malamud, M. (2014). El nuevo militar flexible. Revista Mexicana de Sociología, 76(4), 639-663.

Martínez Herrera, M. (2007). La construcción de la feminidad: la mujer como sujeto de la historia y de deseo. Actualidades en Psicología, 21, 79-95.

Melucci, A. (1989). El tiempo de la diferencia: condición femenina y movimiento de las mujeres. Revista del Departamento de Sociología, 4(10), 1-5.

Mier, I., Pérez, Z., Canto, A,. \& Mier, R. (2007). Interpretando el cuidado. Por qué cuidan sólo las mujeres y qué podemos hacer para evitarlo. Zerbitzuan: Gizarte zerbitzuetarako aldizkariaRevista de Servicios Sociales, 42, 29-38.

Ministerio de Salud y Protección Social. (2015a). Politica nacional de sexualidad, derechos sexuales y derechos reproductivos. Profamilia; UNFPA; OIM. https:/www.minsalud.gov.co/sites/rid/Lists/ BibliotecaDigital/RIDE/DE/LIBRO\%20POLITICA\%20SEXUAL\%20SEPT\%2010.pdf

Ministerio de Salud y Protección Social. (2015b). Encuesta nacional de demografía y salud. Componente de salud sexual y reproductiva (Tomo 2). Profamilia y MinSalud. https://profamilia.org.co/ wp-content/uploads/2019/05/ENDS-2015-TOMO-II.pdf

Moncó Rebollo, B. (2018). Primeras mujeres aviadoras: una construcción cultural entre la exclusión y la ambigüedad. Athenea Digital, 18(1), 365-384. https://doi.org/10.5565/rev/athenea.1912

Moskos, C. (1985). La nueva organización militar: ¿institucional, ocupacional o plural? En J. A. Olmeda Gómez, \& R. Bañón Martínez (Coords.), La institución militar en el Estado contemporáneo. Ed. Alianza, Espańa, p. 140-152. 
Novis Soto, M. L. (1998). Los cuestionarios de personalidad en la selección de pilotos de línea aérea. Revista de Psicología del Trabajo y de las Organizaciones, 14(1), 113-128.

Pachón, X. (2008). La familia en Colombia a lo largo del siglo XX. En Familias, cambios y estrategias (pp. 145-159). Secretaría Distrital de Integración Social, Alcaldía Mayor de Bogotá.

Pena de muerte: sí o no. (1992, noviembre 11). El Tiempo. https://www.eltiempo.com/archivo/documento/MAM-221092

Pérez Adán, J., García, E., \& Iwanowski, M. (2010). Vidas que cuentan. La acción asistencial del movimiento provida como genuina y eficaz acción civil. Bioética AEBI.

Pilicita Caiza, A. P. (2020). El estereotipo de la imagen de la mujer dentro de las Fuerzas Armadas del Ecuador [Tesis de pregrado]. Repositorio Institucional de la Universidad Politécnica Salesiana, sede Quito. https://dspace.ups.edu.ec/handle/123456789/18479

Pimienta, A. (2007). La configuración de la identidad local en la diversidad cultural. Palobra, 8, 60-77.

Profamilia. (1991). Encuesta de prevalencia, demografía y salud. 1990. Profamilia; Institute for Resource Development.

Radkau, V. (1986). Hacia una historiografía de la mujer. Nueva antropología, 8(30), 77-94.

Rial, J. (2009). La mujer en las organizaciones militares en América Latina. En M. Donadio, \& M. Mazzotta (Coords.), La mujer en las instituciones armadas y policiales (pp. 38-49). Redsal.

Richard, N. (1996). Feminismo, experiencia y representación. Revista Iberoamericana, 62(176-177), 733-744.

Rodríguez Menéndez, M. C., \& Fernández García, C. M. (2010). Empleo y maternidad: el discurso femenino sobre las dificultades para conciliar familia y trabajo. Cuadernos de Relaciones Laborales, 28(2), 257-275.

Rubiano, M. P. (2017, septiembre 28). El 65 \% del país le dice sí al aborto legal. El Espectador. https:// www.elespectador.com/noticias/salud/el-65-del-pais-le-dice-si-al-aborto-legal/

Salazar Salazar, J. C. (2019). Rol de la identidad colectiva de las Fuerzas Militares en el proceso de construcción de memoria histórica. En E. Pastrana Buelvas, \& H. Gehring (Eds.), Fuerzas Militares de Colombia: nuevos roles y desafios nacionales e internacionales (pp. 109-142). Fundación Konrad Adenauer, KAS.

Scharff, C. (2019, febrero 17). Por qué tantas mujeres jóvenes no se identifican con el término feminista. BBC News Mundo. https://www.bbc.com/mundo/noticias-47185833

¿Se podrá regular la prostitución en Colombia? (2015, agosto 18). Semana. https://www.semana.com/ nacion/articulo/se-podra-regular-la-prostitucion-en-colombia/438560-3/

Scott, J. (2008). Género e historia. Fondo de Cultura Económica; Universidad Autónoma de la Ciudad de México.

Semidober, I. (2001-2002). Identidad femenina y rol ocupacional. Orientación y Sociedad, 3, 1-16.

Soprano, G. (2013). La profesión militar en los estudios sobre fuerzas armadas y sociedad. Lecturas, interpretaciones y usos desde la Argentina actual. Cuadernos de Marte, 4(5), 63-97.

Sosa, F., Torres, J. A., Fracaroli, C., \& Fernández, O. (2011). Igualdad y equidad de género en la formación de estudiantes militares [Ponencia]. III Congreso Internacional de Investigación y Práctica Profesional en Psicología; XVIII Jornadas de Investigación Séptimo Encuentro de Investigadores en Psicología del Mercosur, Universidad de Buenos Aires, Buenos Aires. 
Sullivan, T. (2014). Greedy institutions, overwork, and work-life balance. Sociological Inquiry, 84(1), 1-15. https://doi.org/10.1111/soin.12029

Thurow, L. (1997, febrero 2). La familia tradicional está en proceso de extinción. El País. https:// elpais.com/diario/1997/02/03/opinion/854924403_850215.html

Tovar Cabrera, G. (2018). Las alas en las botas de los soldados. División de Aviación Asalto Aéreo; ESAVE.

Tovar Cabrera, G. (2020). La Quinta Arma. Historia de la Aviación del Ejército de Colombia. Escuela Militar de Cadetes “General José María Córdova”. https://doi.org/10.21830/9789585287822

Urrego, L. G. (2019). Aviadores con corazón de soldado: aproximación histórica a la Aviación del Ejercito [Tesis de maestría]. Pontificia Universidad Javeriana.

Villalobos, P. (2007). La participación de las mujeres en las Fuerzas Armadas y de Orden. Politicas para promover la inserción de la mujer en la vida pública [Mesa de Trabajo Pro-Género]. Fundación Chile 21 y Fundación Friedrich Ebert, Santiago de Chile, Chile.

Vizcaíno Villa, A. (2019). Equidad de género en el marco de la convivencia social, discursos y prácticas disciplinares: una experiencia investigativa en la escuela militar. Palobra, 19(1), 62-76.

Yago Alonso, C., \& Paterna Bleda, C. (2005). Las implicaciones del feminismo para la identidad social de las mujeres. Anuario de Psicología, 36(2), 143-157.

Zárate Angarita, E. (2014, junio 29). El derecho a la libertad sexual. El Espectador. https://www. elespectador.com/noticias/salud/el-derecho-a-la-libertad-sexual/ 